\title{
ESAT-6-dependent cytosolic pattern recognition drives noncognate tuberculosis control in vivo
}

\author{
Andreas Kupz,, ${ }^{1,2}$ Ulrike Zedler, ${ }^{1}$ Manuela Stäber, ${ }^{1}$ Carolina Perdomo, ${ }^{1}$ Anca Dorhoi, ${ }^{1}$ Roland Brosch, ${ }^{3}$ and Stefan H.E. Kaufmann ${ }^{1}$ \\ ${ }^{1}$ Max Planck Institute for Infection Biology, Berlin, Germany. ${ }^{2}$ Centre for Biosecurity and Tropical Infectious Diseases, Australian Institute of Tropical Health and Medicine, James Cook University, \\ Cairns, Queensland, Australia. ${ }^{3}$ Institut Pasteur, Unit for Integrated Mycobacterial Pathogenomics, Paris, France.
}

\begin{abstract}
IFN- $\gamma$ is a critical mediator of host defense against Mycobacterium tuberculosis (Mtb) infection. Antigen-specific CD4 ${ }^{+} \mathrm{T}$ cells have long been regarded as the main producer of IFN- $\gamma$ in tuberculosis (TB), and CD4+ $T$ cell immunity is the main target of current TB vaccine candidates. However, given the recent failures of such a TB vaccine candidate in clinical trials, strategies to harness CD4-independent mechanisms of protection should be included in future vaccine design. Here, we have reported that noncognate IFN- $\gamma$ production by Mtb antigen-independent memory CD8 ${ }^{+} \mathrm{T}$ cells and NK cells is protective during Mtb infection and evaluated the mechanistic regulation of IFN- $\gamma$ production by these cells in vivo. Transfer of arenavirus- or protein-specific CD8+ T cells or NK cells reduced the mortality and morbidity rates of mice highly susceptible to TB in an IFN- $\gamma-$ dependent manner. Secretion of IFN- $\gamma$ by these cell populations required IL-18, sensing of mycobacterial viability, Mtb protein 6-kDa early secretory antigenic target-mediated (ESAT-6-mediated) cytosolic contact, and activation of NLR family pyrin domain-containing protein 3 (NLRP3) inflammasomes in CD11c cell subsets. Neutralization of IL-18 abrogated protection in susceptible recipient mice that had received noncognate cells. Moreover, improved Mycobacterium bovis bacillus CalmetteGuérin (BCG) vaccine-induced protection was lost in the absence of ESAT-6-dependent cytosolic contact. Our findings provide a comprehensive mechanistic framework for antigen-independent IFN- $\gamma$ secretion in response to Mtb with critical implications for future intervention strategies against TB.
\end{abstract}

\section{Introduction}

Mycobacterium tuberculosis (Mtb), the causative agent of tuberculosis (TB), continues to cause considerable global morbidity and mortality, with approximately 9.6 million new cases and 1.5 million deaths in $2014(1,2)$. Resurgence of TB is also the number-one cause of death in HIV-infected individuals, particularly in endemic areas of sub-Saharan Africa $(1,3)$. This catastrophic situation is in part due to the low efficiency of the only licensed antiTB vaccine, bacillus Calmette-Guérin (BCG), in affording protection against pulmonary $\mathrm{TB}$ and preventing disease transmission (1). Despite the availability of effective TB drugs, poor adherence to long treatment regimens of at least 6 months not only worsens the situation for the individual patient but also contributes to the emergence of drug-resistant $M t b$ strains.

Upon inhalation, $M t b$ bacilli are taken up by, and are capable of persisting within, myeloid cell populations in the lung over prolonged periods of time, and sterile eradication is rarely achieved. An estimated one-third of the world's population is latently infected with $M t b$ without showing signs of active TB disease (4). $M t b$ uses a variety of sophisticated effector molecules that can interfere with a multitude of cellular functions including pattern recognition, antigen presentation, and phagolysosome formation, thereby quickly establishing an intracellular survival niche, where it hides from the host's innate and adaptive immune response $(5,6)$. The use of such pathogenic decoy and evasion mechanisms not only contributes to

Conflict of interest: The authors have declared that no conflict of interest exists. Submitted: October 5, 2015; Accepted: March 8, 2016.

Reference information: J Clin Invest. 2016;126(6):2109-2122. doi:10.1172/JCI84978. the success of $M t b$ but also provides significant challenges for the development of effective new intervention measures (6).

Containment of $M t b$ infection requires functional $\mathrm{CD} 4^{+} \mathrm{T}$ cell responses (7), in particular the production of IFN- $\gamma$ and the formation of granulomatous lesions (8). In the absence of $\mathrm{CD}^{+} \mathrm{T}$ cells, IFN- $\gamma$, its receptor, or downstream effector molecules such as inducible NOS (iNOS), susceptibility and disease are exacerbated (9-11). Accordingly, coinfection with HIV, which impairs CD4 ${ }^{+} \mathrm{T}$ cells during its reproduction, is one of the major factors contributing to the spread of $\mathrm{TB}$ (12). Impairment of $\mathrm{CD}^{+} \mathrm{T}$ cells compromises the integrity of TB lung granulomas, eliminates a major source of IFN- $\gamma$, and affects the main target of many TB vaccine candidates. Cognate activation and expansion of $M t b$-specific conventional $\mathrm{CD}^{+}{ }^{+} \mathrm{T}$ cells of the Th1 and Th17 lineages through the use of immunodominant antigens, such as Ag85 cognates, is the main strategy in current TB vaccine development (3). However, the recent failures of the most advanced TB vaccine candidate, MVA85A, in 2 clinical trials (13, 14), as well as the failure of new TB drug treatment regimens (15), highlight an urgent need to reconsider the design of TB intervention. Furthermore, the evolutionary conservation of $M t b$ epitopes for human T cells among many mycobacterial species supports the idea that human $\mathrm{T}$ cells predominantly recognize broadly shared mycobacterial antigens (16) and that $M t b$ can even benefit from cognate $\mathrm{T}$ cell recognition (17). Therefore, it is highly desirable to have a more detailed understanding of how different immune cell populations, such as unconventional T cells, $\gamma \delta \mathrm{T}$ cells, mucosal-associated invariant T (MAIT) cells, invariant NK T (iNKT) cells, CD1-restricted T cells, as well as NK cells and even Ab-producing cells, are activated and participate in a protective immune response against $M t b$ (1). 
In contrast to cognate $\mathrm{T}$ cell receptor/MHC-mediated (TCR/ MHC-mediated) priming of antigen-specific IFN- $\gamma$ secretion by conventional $\mathrm{CD}^{+}$and $\mathrm{CD}^{+} \mathrm{T}$ cells (18), IFN- $\gamma$ secretion can also be antigen independent and driven by cytokines, including IL-18 $(19,20)$. Initially thought to only be produced by NK cells and $\gamma \delta$ $\mathrm{T}$ cells, IL-18-driven IFN- $\gamma$ production was recently expanded to include memory $\mathrm{CD}^{+} \mathrm{T}$ cells as IFN- $\gamma$ producers as well (21-25). Secretion of bioactive IL-18 requires proteolytic cleavage from its biologically inactive precursor pro-IL-18 through caspase-1 (26), which in turn depends on the upstream assembly and activation of inflammasomes through the engagement of cytosolic pattern recognition receptors (PRRs) (26). Intriguingly, not only have deficiencies in caspase- 1 and IL-18 $(27,28)$ been implicated in impaired immunity to $M t b$, but a deficiency in a PRR that is required for the upstream activation of caspase-1 has been implicated as well (29). These results point to an important host-protective role for the caspase-1/IL-18/IFN- $\gamma$ axis and suggest that strategies aimed at targeting cytosolic PRRs beyond adjuvant immunotherapy (30) could serve as a means of inducing IL-18-mediated IFN- $\gamma$ production to control $M t b$ infections.

Consistent with this hypothesis, it was recently demonstrated in a model of experimental Listeria monocytogenes infection that rapid, cytokine-driven IFN- $\gamma$ secretion by memory $\mathrm{CD}^{+} \mathrm{T}$ cells significantly orchestrates host innate immune responses and has an impact on the magnitude of the recall response after vaccination (31). Vaccination strategies that are independent from specific TCR-MHC interactions could therefore be an attractive target to induce host-protective IFN- $\gamma$ production as well as a means to overcome $M t b$-induced MHC downregulation and the reliance on mostly unknown $M t b$-nonspecific MHC antigens (16) that might even benefit the pathogen rather than the host (17). Therefore, using an established murine model of TB, our study aimed to investigate whether $M t b$-independent immune responses contribute to immunity against $M t b$ and, if so, to dissect their mechanistic regulation in vivo as well as to elucidate potential applications for vaccine improvement and host-directed therapeutic approaches.

\section{Results}

Noncognate cell sources of IFN- $\gamma$ are sufficient to mediate early control of $M t b$ infection. We harnessed an experimental TB model in mice to determine whether memory $\mathrm{CD}^{+} \mathrm{T}$ cells and NK cells unrelated to $M t b$ can mediate protection against TB. Whereas WT C57BL/6 (B6) mice are relatively resistant to a low-dose aerosol infection with $M t b$ H37Rv (Figure 1A), mice that lack IFN- $\gamma$, the IFN- $\gamma$ receptor, or

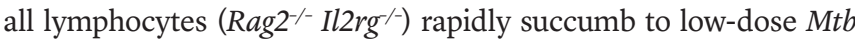
infection within approximately 30 days (refs. 11, 32, 33, and Figure 1A). Given that noncognate immune cells can provide protection against $M t b$ in the absence of other lymphocytes, adoptive transfer of mycobacteria-independent memory $\mathrm{CD}^{+} \mathrm{T}$ cells or selected NK cells should significantly prolong the survival of Rag $2^{-/-} \mathrm{Il} 2 \mathrm{rg}^{-/-}$mice.

To investigate this hypothesis, we generated both OVA- and lymphocytic choriomeningitis virus-specific (LCMV-specific) MHC class I-restricted effector CD8 ${ }^{+} \mathrm{T}$ cells $(34,35)$ and then purified and adoptively transferred them into naive Rag2 $2^{-/-} \mathrm{Il}_{2 \mathrm{rg}^{-/}}$mice (Supplemental Figure 1; supplemental material available online with this article; doi:10.1172/JCI84978DS1). In this model system, within weeks, these T cells convert into central memory $\mathrm{T}$ cells with speci- ficity for either the SIINFEKL epitope of the OVA protein (OT-ITg) or the KAVYNFATC epitope of the LCM virus (P14Tg), respectively (36, 37). Transfer of either OT-ITg or P14Tg memory CD8 ${ }^{+} \mathrm{T}$ cells more than doubled the mean survival time for Rag2 $2^{-1-} \mathrm{Il}_{2 g^{-/-}}$mice (Figure 1A). In contrast, treatment with anti-IFN- $\gamma$ Ab after transfer of OT-ITg cells into $\mathrm{Rag2}^{-/-} \mathrm{Il}_{2 \mathrm{rg}^{-/}}$mice (Figure 1A) or transfer of OT-ITg cells into Ifngr/- mice did not prolong survival (Figure 1B), indicating that host protection by noncognate memory $\mathrm{CD}^{+} \mathrm{T}$ cells involves downstream effects of IFN- $\gamma$. Similarly, when in vitro-expanded purified NK cells were transferred into Rag2 $2^{-/-} \mathrm{Il} 2 \mathrm{rg}^{-/-}$mice, survival time was substantially prolonged and reverted almost to the survival time of Rag1/-- mice, which naturally contain NK cells (Figure 1A). In contrast, the transfer of Ifng $g^{-/} \mathrm{NK}$ cells did not prolong the survival of $\mathrm{Rag}^{-1-} \mathrm{Il}_{2 \mathrm{rg}}^{-/}$mice (Figure 1A). These results demonstrate an inherent capacity of $M t b$-unrelated virus- and OVA-specific memory $\mathrm{CD}^{+} \mathrm{T}$ cells as well as NK cells to mediate early IFN- $\gamma$-dependent control of TB in the absence of other lymphocytes.

To address whether noncognate cells also improved the control of $M t b$ infection in immunocompetent hosts, we additionally transferred OT-ITg cells into B6 (CD45.1 $1^{+}$mice (Figure 1, C and D and Supplemental Figure 1). Four weeks later, when OT-ITg cells had converted into central memory $\mathrm{T}$ cells, the mice were aerosol infected with $M t b$. Consistent with previous findings, immunocompetent B6 mice were resistant to $M t b$ and only succumbed to the infection after 200 to 300 days (Figure 1A). To exclude the effects of endogenous $\mathrm{T}$ cell responses, we focused on early time points measuring bacterial loads in lung and spleen 7 and 14 days post infection (p.i.). At both time points, the transfer of OT-ITg cells significantly reduced bacterial numbers in the lung (Figure 1E) and slowed the progression of $M t b$ to the spleen (Figure $1 \mathrm{~F}$ ). Whereas 7 of 9 control mice had $M t b$ in the spleen 14 days p.i., only 3 of 11 mice that received OT-ITg cells did. Collectively, these results demonstrate that $M t b$-unrelated memory $\mathrm{CD}^{+} \mathrm{T}$ cells improve early protection against $\mathrm{M} t b$, not only in immunocompromised but also in immunocompetent hosts.

Innate IFN- $\gamma$ secretion in response to $M t b$ requires bacterial viability and $I L-18$. Next, we addressed the mechanistic requirements of how $M t b$-unrelated memory $\mathrm{CD}^{+} \mathrm{T}$ cells and NK cells secrete IFN- $\gamma$ in response to $M t b$. Noncognate production of IFN- $\gamma$ in response to other pathogens such as Salmonella enterica serovar typhimurium (Stm), Pseudomonas aeroginosa, and L. monocytogenes has been linked to the upstream effects of IL-18 (21-23). To interrogate whether and how early IFN- $\gamma$ secretion in response to mycobacteria requires IL-18, we established a short-term in vivo exposure model, in which naive B6 mice were exposed to either live or dead mycobacteria for a maximum of 48 hours. At 2, 18, 24, and 48 hours after exposure, IFN- $\gamma$ secretion by $\mathrm{CD} 3^{+} \mathrm{CD} 4^{+}, \mathrm{CD} 3^{+} \mathrm{CD} 8^{+}$, $\mathrm{CD}^{+}{ }^{+} \mathrm{CD} 4^{-} \mathrm{CD}^{-}$(double-negative [DN]), and $\mathrm{CD}^{-} \mathrm{NK} 1.1^{+}$cells in lung, spleen, and lymph nodes (LNs) was assessed directly ex vivo. Because antigen-specific $\mathrm{T}$ cell responses take at least 3 to 4 days to develop (38), any IFN- $\gamma$ secretion observed within a 48-hour time frame in $M t b$-naive mice must be unrelated to $M t b$.

In contrast to Stm, which induces IFN- $\gamma$ secretion by non-CD 4 immune cells within 2 hours (ref. 21 and Figure 2A), neither live or inactivated BCG nor $M t b$ was able to induce IFN- $\gamma$ secretion within 2 hours after i.v. injection (Figure 2A and Supplemental Figure 2, A and B). BCG, heat-killed BCG (HKBCG), and irradiated Mtb H37Rv (iMtb) did not induce any IFN- $\gamma$ over a 48-hour period (Sup- 

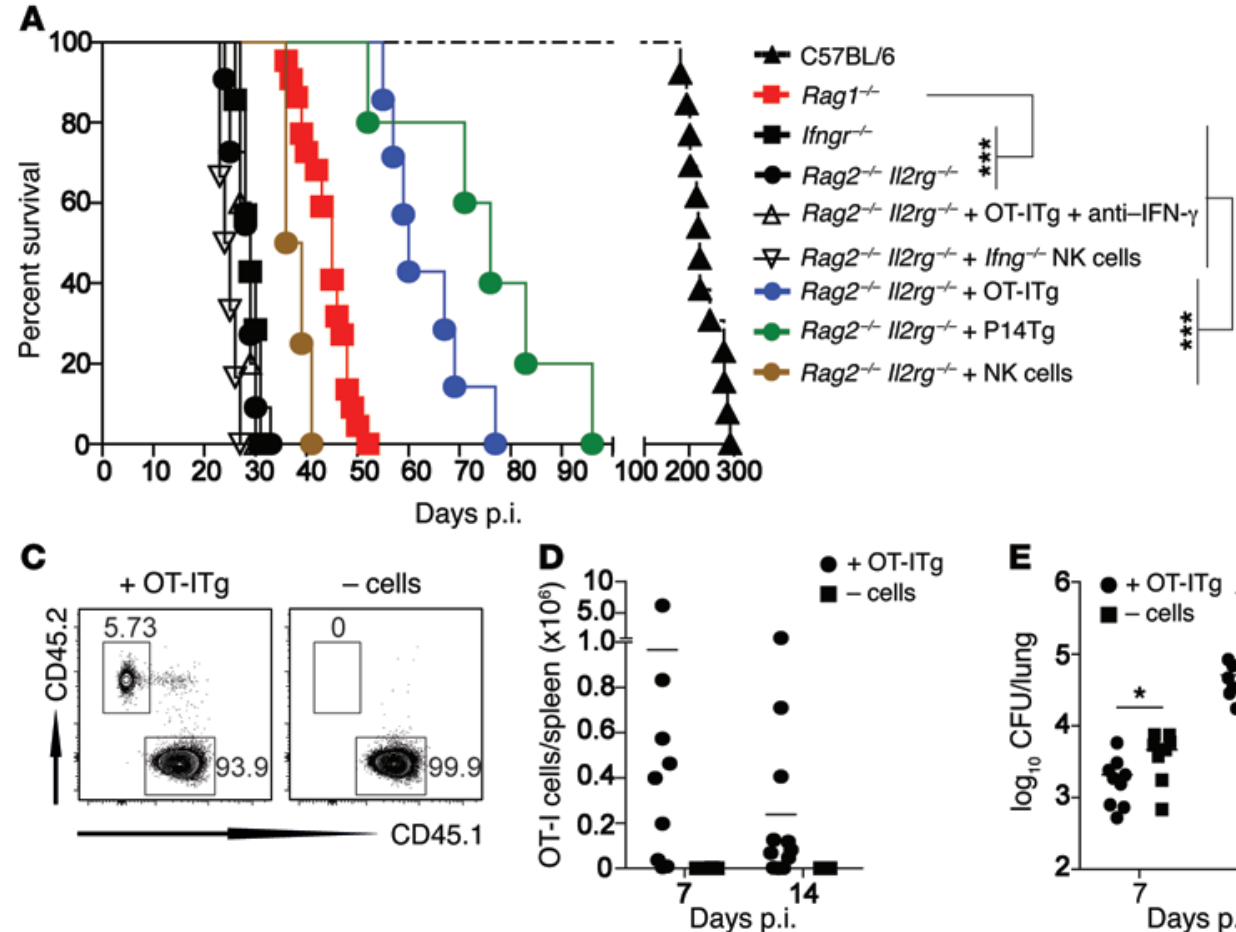
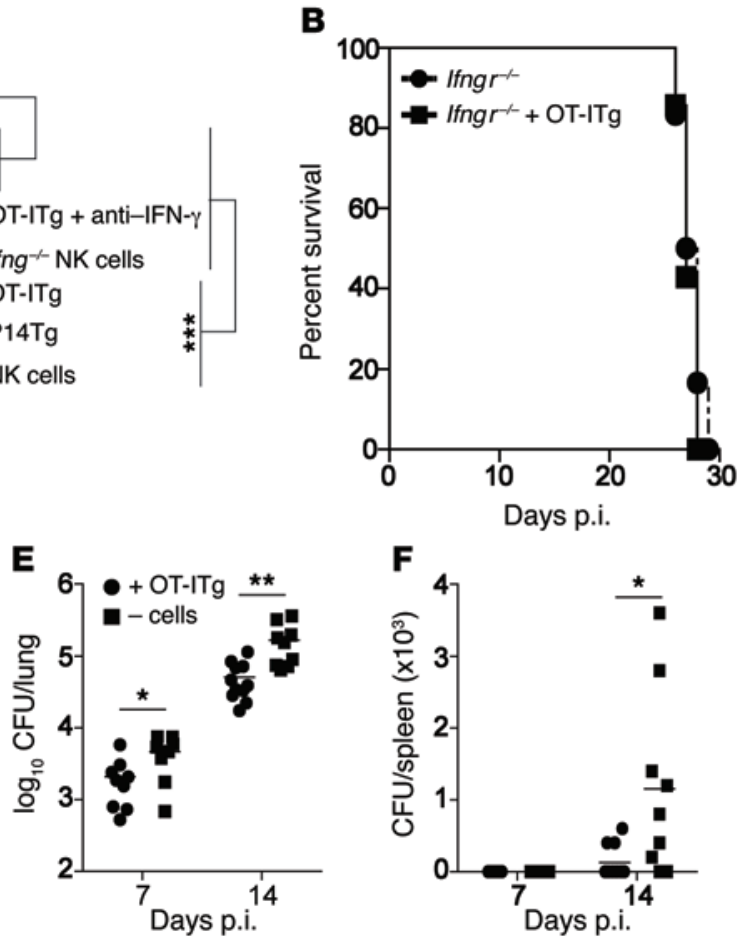

Figure 1. Noncognate memory CD8 ${ }^{+} \mathrm{T}$ cells and NK cells are sufficient to mediate early IFN- $\gamma$-dependent control of Mtb infection. (A-F) Naive B6,

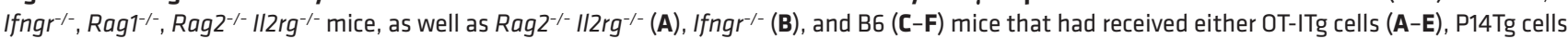
(A), NK cells, or Ifng ${ }^{-/}$NK cells (A) were infected with 200 CFU Mtb H37Rv via the aerosol route, and survival (A and B), OT-ITg cell numbers among CD8 ${ }^{+} \mathbf{T}$ cells (C and $\mathbf{D}$ ), and CFU (E and $\mathbf{F}$ ) were assessed over time. For neutralization of IFN- $\gamma(\mathbf{A})$, mice received weekly i.p. injections of $200 \mu \mathrm{g}$ anti-IFN- $\gamma$ mAb. Results are presented as individual data points (D-F), pooled data means (A and B), or representative FACS plots (C) of 7 to 22 (A), 7 (B), and 8 to 11 (C-F) mice per group from 2 (B-F) or 5 (A) pooled, independent experiments. ${ }^{*} P<0.05,{ }^{*} P<0.01$, and ${ }^{* *} P<0.001$, by log-rank (Mantel-Cox) test (A and $\mathbf{B}$ ) or unpaired, 2-tailed Student's $t$ test per time point (E and $\mathbf{F})$.

plemental Figure 2A). In contrast, significant production of IFN- $\gamma$ in response to live $M t b \mathrm{H} 37 \mathrm{Rv}$ was detected at 18 hours and peaked at approximately 24 hours after i.v. injection (Figure 2B). Approximately $40 \%$ of NK cells (30\% in the lung), $8 \%$ of DN T cells (4\%$5 \%$ in the lung), and $2 \%$ of $\mathrm{CD}^{+} \mathrm{T}$ cells in the spleen secreted IFN- $\gamma$ 24 hours after systemic $M t b$ exposure (Figure 2B and Supplemental Figure 2B). Further phenotypic characterization of IFN- $\gamma$-producing DN T cells revealed an equal ratio of $\alpha \beta \mathrm{TCR}^{+}$and $\gamma \delta \mathrm{TCR}^{+}$ cells (Supplemental Figure 2C). All IFN- $\gamma$-producing $\mathrm{CD} 8^{+} \mathrm{T}$ cells stained positive for CD44 and CD62L and displayed a diverse TCR $\mathrm{V} \beta$ chain usage (Supplemental Figure 2C). These results identify IFN- $\gamma$-producing $\mathrm{CD}^{+} \mathrm{T}$ cells as multispecific central memory $\mathrm{T}$ cells (39), making it unlikely that these $\mathrm{T}$ cells possess an alternative TCR specific for $M t b$, as has been suggested for $\mathrm{CD} 4^{+} \mathrm{Tg} \mathrm{T}$ cells (40). In line with these findings, transferred OT-ITg cells displayed a central memory phenotype 4 weeks after adoptive transfer and secreted IFN $\gamma 24$ hours after $M t b$ challenge (Supplemental Figure 2D), confirming that the response was noncognate. Importantly, serum IL-18 concentrations correlated with the strength of IFN- $\gamma$ production, and IL-18 was detected only after injection of live Mtb but not live BCG or iMtb (Figure 2C and Supplemental Figure 2E).

In contrast to i.v. injection, which induced a strong, dose-dependent systemic IFN $-\gamma$ response (Figure 2D), Mtb administration via the intradermal (i.d.), subcutaneous (s.c.), or intratracheal (i.t.) infection route induced only local, tissue-restricted IFN- $\gamma$ secretion and significantly lower secretion of IL-18 (Figure 2E and Sup- plemental Figure 2E). Of note, the strength of the IFN- $\gamma$ response correlated with the amount of viable bacteria in the respective tissue (Figure 2F), starting with a minimal number of $1,000 \mathrm{CFU}$ in the organ 24 hours p.i. (dotted line, Figure $2 \mathrm{~F}$ ) to obtain a reliable IFN- $\gamma$ response ( $2 \%$ LN s.c.; dotted line Figure $2 \mathrm{E}$ ). Given the often reduced number of recoverable bacteria relative to the infectious dose, these results could explain why an aerosol infection with $1,000 \mathrm{CFU} M t b \mathrm{H} 37 \mathrm{Rv}$ did not induce a detectable IFN- $\gamma$ response in this model (Supplemental Figure 2F). Collectively, these results support the requirement for a spatially distinct pattern of pathogen recognition (22) and suggest that the presence of high numbers of live bacteria within the tissue is a crucial requirement for rapid, noncognate IFN- $\gamma$ production. We conclude that innate IFN- $\gamma$ secretion in response to $M t b$ depends on the sensing of viable bacteria and is driven by the secretion of IL-18. Given the ubiquitous distribution and magnitude of IFN- $\gamma$ secretion by $\mathrm{CD} 3-\mathrm{NK} 1.1^{+}$and $\mathrm{CD}^{+} \mathrm{CD} 8^{+}$ cells 24 hours after i.v. Mtb injection, we subsequently focused on these cell types and the timing following an i.v. infection route for further dissection of the underlying mechanistic requirements.

Innate IFN- $\gamma$ depends on RD1 and ESAT-6-mediated cytosolic contact. Live BCG did not lead to an IFN- $\gamma$ response, suggesting that $M t b$ virulence factors play a critical role. To identify the underlying mechanisms, we further probed the bacterial factors that drive early, IL-18-dependent IFN- $\gamma$ secretion by exposing naive B6 mice to a panel of recombinant bacterial strains or $M t b$ components for 24 hours. 

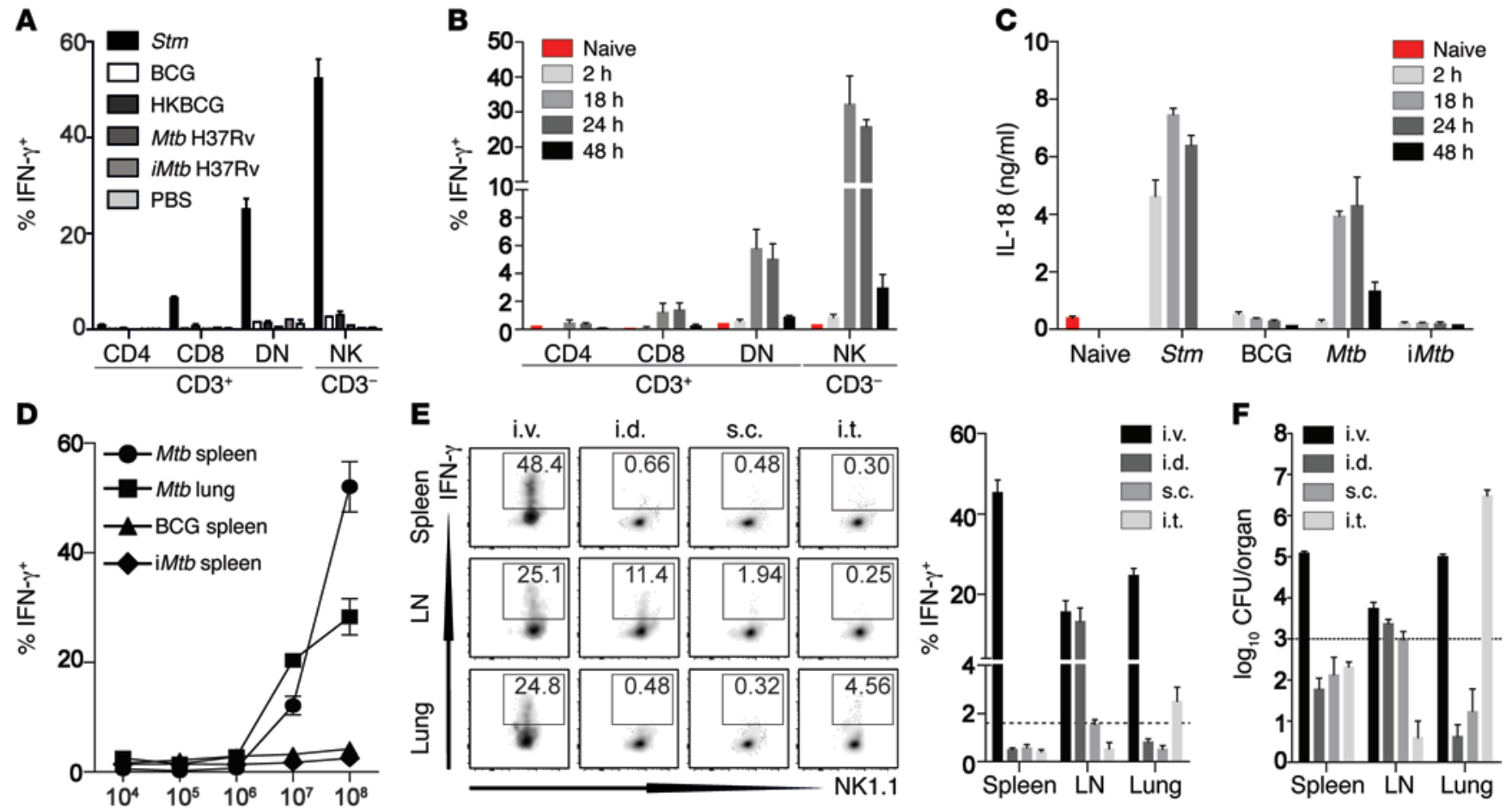

Figure 2. Innate IFN- $\gamma$ secretion depends on IL-18 and requires Mtb viability. (A) Percentage of IFN- $\gamma^{+}$cells among total viable splenic CD3+CD8 ${ }^{+}$, $\mathrm{CD3}^{+} \mathrm{CD}^{+}, \mathrm{CD}^{+} \mathrm{CD} 4^{-} \mathrm{CD} 8^{-}(\mathrm{DN}) \mathrm{T}$ cells and CD3-NK1.1+ cells 2 hours after B6 mice were injected with $1 \times 10^{8} \mathrm{CFU}$ of either Stm (as a positive control), BCG, HKBCG, Mtb H37Rv, iMtb, or PBS. (B) Percentage of IFN- $\gamma^{+}$cells among total viable splenic CD3+CD8 ${ }^{+}, \mathrm{CD3}^{+} \mathrm{CD} 4^{+}, \mathrm{CD}^{+} \mathrm{CD} 4^{-} \mathrm{CD} 8^{-}$(DN) T cells and CD3-NK1.1+ cells at different time points after B6 mice were injected with $1 \times 10^{8}$ CFU Mtb H37Rv. (C) Serum IL-18 concentrations at different time points after injection of B6 mice with $1 \times 10^{8}$ CFU Stm, BCG, Mtb H37Rv, or iMtb H37Rv. (D) Percentage of IFN- $\gamma^{+}$cells among total viable CD3-NK1.1 in spleen and lung 24 hours after injection of different doses of Mtb H37Rv, BCG, or iMtb H37Rv. (E and F) Percentage of IFN- $\gamma^{+}$CD3-NK1.1 ${ }^{+}$cells (E) and recoverable CFU (F) from either spleen, lung, or draining LN 24 hours after injection of $1 \times 10^{8} \mathrm{CFU} M t b$ H37Rv via the i.v., i.d., i.t., or s.c. route. Results are presented as pooled data (mean \pm SEM) (A-F) and representative FACS plots (E) of 5 to 9 (A), 5 to 10 (B and C), 5 (D), or 7 to 10 (E and F) mice per group from at least 2 to 3 pooled, independent experiments. Dotted lines indicate the mean percentage of the smallest reliably detectable IFN- $\gamma^{+}$response by CD3-NK1.1 $1^{+}$cells (E) and the respective mean recoverable CFU (F) 24 hours after Mtb exposure.

Consistent with our previous results, neither purified $M t b$ components, including the cell wall, cell membrane, whole-cell lysates, cytosolic components, and DNA, nor BCG induced IL-18 or IFN- $\gamma$ secretion (Figure 3, A, B, D, E, G, and H, and Supplemental Figure $3, \mathrm{~A}, \mathrm{~B}, \mathrm{D}$, and $\mathrm{E})$. Moreover an $M t b \Delta$ region of difference $1(\Delta \mathrm{RD} 1)$ mutant (41) that lacks the RD1, encoding parts of the ESX-1 type VII secretion system that is absent from all BCG strains $(41,42)$, failed to induce rapid IL-18-dependent IFN- $\gamma$ secretion (Figure 3, C, F, and I, and Supplemental Figure 3, C and F). In contrast, when a BCG strain reconstituted with the extended RD1 locus from Mtb (BCG::RD1) (43) was used, production of both IL-18 and IFN- $\gamma$ was restored (Figure 3, C, F, and I, and Supplemental Figure 3, C and F-H), pointing to a crucial role of the RD1-encoded ESX-1 secretion system. Using a panel of recombinant BCG::RD1 and $M t b$ strains, we identified the es $x A$ gene within the $\mathrm{RD} 1$ locus as indispensable for production of both IL-18 and IFN- $\gamma$ (Figure 3, C, F, and I, and Supplemental Figure $3, \mathrm{C}$ and $\mathrm{F})$. The es $x A$ gene encodes for the 6-kDa early secretory antigenic target (ESAT-6), a prominent immunogen and virulence factor of $M t b(44,45)$. Neither $M t b \Delta$ ESAT-6 (46) nor a recombinant BCG::RD1 strain secreting C-terminal-truncated ESAT-6 (BCG::RD1 ESAT-6 $\Delta 92-95)$ induced production of IL-18 or IFN- $\gamma$ (Figure 3, C, F, and I, and Supplemental Figure 3, C and F). These results relate to previous work, in which tubercle bacilli that did not produce ESAT- 6 or that lacked the C-terminal end of ESAT- 6 were unable to induce phagosomal rupture and establish cytosolic contact (47). Overall, these results suggest that a functional RD1 locus and ESAT-6-mediated cytosolic contact are required to induce IL-18-dependent IFN- $\gamma$ secretion in response to $M t b$ in vivo.

Innate IF $N-\gamma$ depends on canonical NLRP3 signaling. We next set out to determine the host signaling pathways required for innate IFN- $\gamma$ production. To this end, we took advantage of a panel of genetically modified mouse strains that received $M t b \mathrm{H} 37 \mathrm{Rv}$ i.v.

The absence of rapid IFN- $\gamma$ production in $\mathrm{Il1}^{-/}$mice confirmed our previous results demonstrating a direct correlation between IL-18 secretion and IFN- $\gamma$ secretion (Figure $4, \mathrm{~A}-\mathrm{C}$, and Supplemental Figure 4, A and B). Since secretion of bioactive IL-18 depends on the enzymatic cleavage of pro-IL-18 by caspase-1 (26), we tested caspase- $1^{-/-}$mice and found that they failed to secrete IL-18 and IFN- $\gamma$ (Figure 4, A-C, and Supplemental Figure 4, A and B). Activation of caspase- 1 involves the sensing of danger molecules or stress signals via upstream cytosolic PRRs, so-called inflammasomes (26), and this process can be enhanced and controlled via TIR domain-containing adaptor-inducing IFN- $\beta$ (TRIF-dependent) caspase-11 activation (48). Although caspase-1 and -11 double-KO mice failed to respond to $M t b$ challenge, the response in caspase-11/-- single-KO mice was indistinguishable from that in B6 controls, indicating a requirement for caspase-1-mediated cleavage and excluding noncanonical caspase-11 involvement (Figure 
A

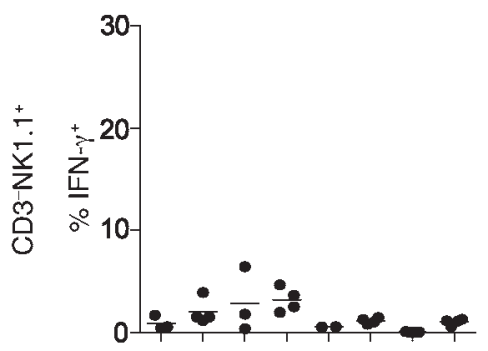

D

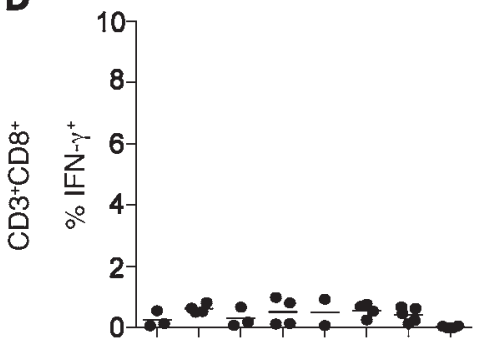

G

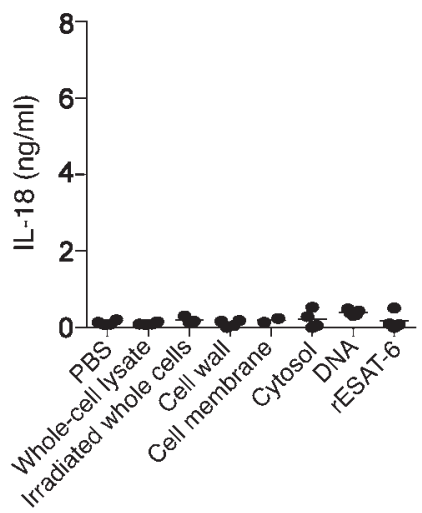

B

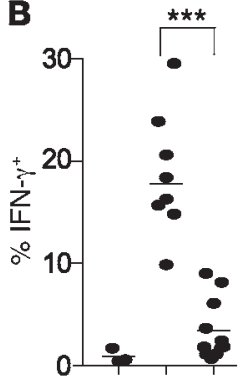

E

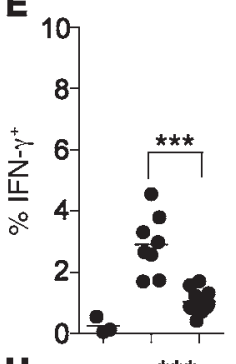

H

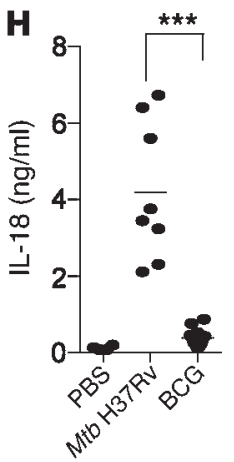

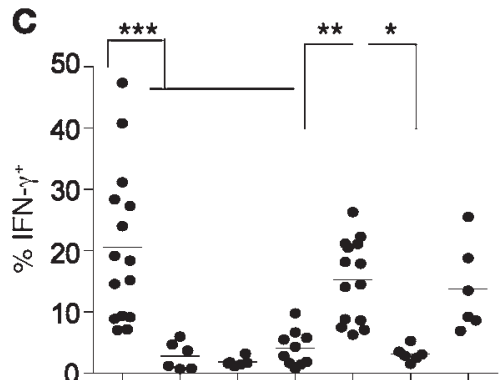

F

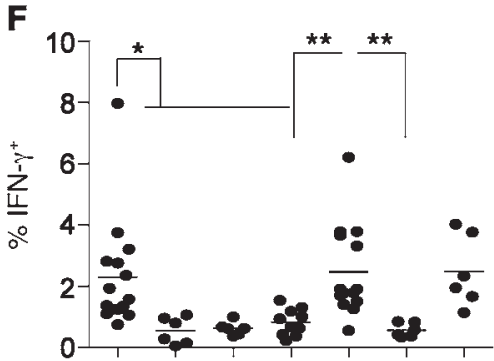

I

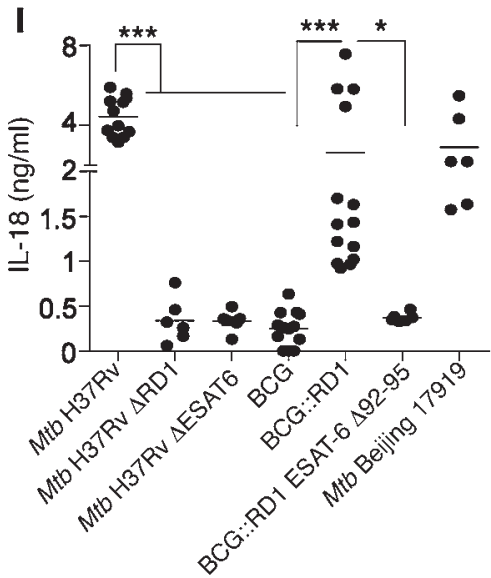

Figure 3. Innate IFN- $\gamma$ depends on RD1 and ESAT-6-mediated cytosolic contact. (A-F) Percentage of IFN $-\gamma^{+}$cells among total viable $\mathrm{CD3}^{-} \mathrm{NK}^{-1} 1^{+}(\mathbf{A}-\mathbf{C})$ and $\mathrm{CDB}^{+} \mathrm{CD}^{+}$ (D-F) lung cells and serum IL-18 concentrations (G-I) 24 hours after B6 mice were injected with different purified mycobacterial ligands (A, D, and $\mathbf{C}$ ) or $1 \times 10^{8} \mathrm{CFU}$ WT or recombinant Mtb or BCC strains (B, C, E, F, $\mathbf{H}$, and $\mathbf{I}$.). Individual data points of 3 to 15 mice per group from at least 2 pooled, independent experiments are shown. ${ }^{*} P<0.05,{ }^{* *} P<0.01$, and ${ }^{* *} P<0.001$, by 1 -way ANOVA. rESAT-6, recombinant ESAT-6.
4, A-C, and Supplemental Figure 4, A and B). Accordingly, NLR family pyrin domain-containing protein 3 (NLRP3) and apoptosisassociated speck-like protein containing a carboxy terminal CARD (ASC), molecules involved in canonical activation of caspase-1 (26), were crucial, since secretion of both IL-18 and IFN- $\gamma$ was impaired in $\mathrm{Nlrp3}^{-/-}$and $\mathrm{Asc}^{-/-}$mice (Figure 4, A-C, and Supplemental Figure $4, \mathrm{~A}$ and $\mathrm{B}$ ). To determine the involvement of cytosolic DNA recognition, which has been suggested to be a host defense mechanism against $M t b(29,49-51)$, we also tested mice lacking the cytosolic DNA sensors stimulator of IFN genes (STING) and absent in melanoma 2 (AIM2). Both, Sting ${ }^{--}$and Aim2 $2^{-/-}$mice secreted levels of IL-18 and IFN- $\gamma$ that were comparable to those in control animals, excluding a role for cytosolic DNA sensing (Figure 4, A-C, and Supplemental Figure 4, A and B). Furthermore, the response did not require IL-1 $\beta\left(\mathrm{Il1b}^{-/-}\right)$or TLR2/4 (Tlr2 $\left.2^{-/-} / \mathrm{Tlr}^{-/-}\right)$, was independent of upstream type I IFN signaling (Ifnabr/-), and did not depend on IL-15 (23) (Figure 4, A-H, and Supplemental Figure 4, A-F). However, IFN- $\gamma$ secretion depended on IL-18 receptor signaling, because IFN- $\gamma$ production, but not IL-18 secretion, was impaired in $M y d 88^{-/}$mice (Figure $4, \mathrm{~A}^{-} \mathrm{C}$, and Supplemental Figure 4, A and $\mathrm{B})$, indicating that MyD88 signaling must occur downstream of the IL-18 receptor, but not downstream of TLRs. A slight reduction in secretion of both IL-18 and IFN- $\gamma$ by NK cells in the lung was observed in $\mathrm{fngr}^{--}$mice (Figure 4, D-F). This might be due to a positive feedback loop for IFN- $\gamma$ that has been reported previously for the secretion of IL-1 $\beta$ (52) or to a lower induction of NK cellrecruiting chemokines in the absence of IFN- $\gamma$ signaling $(53,54)$.

Taken together, these results indicate that rapid, noncognate IFN- $\gamma$ secretion in vivo in response to $M t b$ depends on the NLRP3/ caspase-1/IL-18 axis. Although ESAT- 6 has been shown to be both necessary and sufficient to activate the NLRP3 inflammasome in vitro (55), the underlying mechanisms remain unclear. Given the membrane-damaging features of ESAT- $6(41,56)$, the suggested perturbation of host cell membranes to induce a potassium efflux (55) provides a possible explanation. However, in our system, cytosolic NLRP3 activation appears to at least be independent of $\mathrm{P} 2 \mathrm{X}_{7}$ receptor-dependent potassium efflux, since $\mathrm{P} 2 x 7 \mathrm{r}^{-/-}$mice secreted both IL-18 and IFN- $\gamma$ in response to $M t b$ (Figure 4, D-F, and Supplemental Figure 4, C and D).

$D C$ s are required for $I L-18$ secretion. In order to potentially target ESAT-6-dependent NLRP3 activation for preventive or therapeutic intervention strategies, it would be desirable to identify the $M t b$-sensing and IL-18-secreting cell type in vivo.

Thus, to determine whether IL-18 needs to be secreted by a hematopoietic or nonhematopoietic cell type, we generated BM chimeras and analyzed IFN- $\gamma$ secretion in spleen and lung as well 

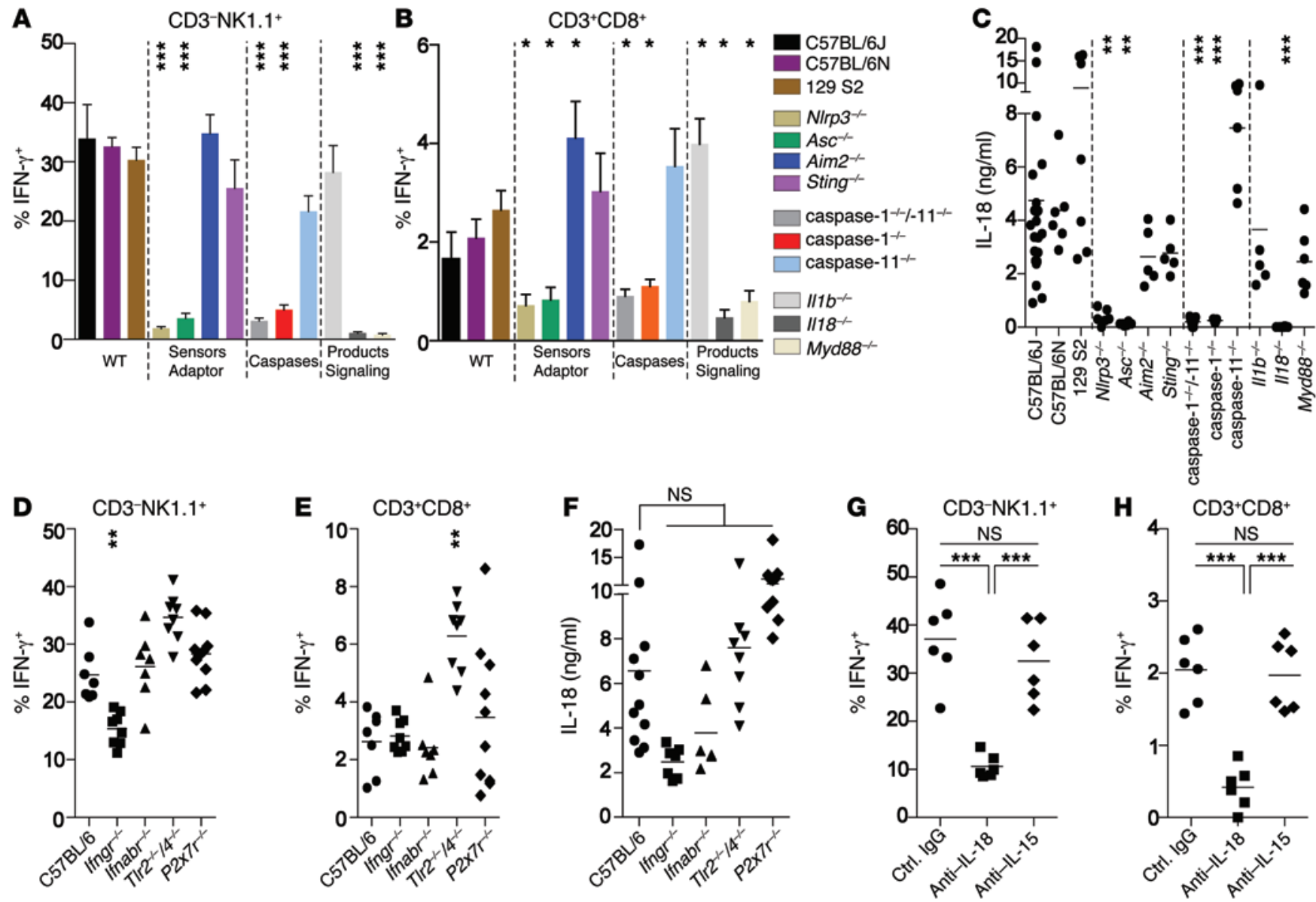

Figure 4. IL-18-dependent IFN- $\gamma$ secretion requires canonical NLRP3 signaling and is independent of surface receptor engagement. Percentage of viable lung IFN- $\gamma^{+}$cells among total CD3-NK1.1 $1^{+}(\mathbf{A}$ and $\mathbf{D})$ and $\mathrm{CD3}^{+} \mathrm{CD}^{+}(\mathbf{B}$ and $\mathbf{E})$ cells and serum IL-18 concentrations $\left(\mathbf{C}\right.$ and $\mathbf{~ F ) ~} 24$ hours after i.v. injection of $1 \times 10^{8}$ CFU Mtb H37Rv into different strains of mice lacking either key components of cytosolic PRR pathways (A-C) or key surface receptors involved in Mtb recognition and innate immune responses ( $\mathbf{D}-\mathbf{F})$, or into B6 mice treated with different $A$ bs $(\mathbf{G}$ and $\mathbf{H})$. Results are presented as pooled data (mean $\pm S E M)(\mathbf{A}$ and B) or as individual data points $(\mathbf{C}-\mathbf{H})$ of 5 to $16(\mathbf{A}-\mathbf{C}), 7$ to $10(\mathbf{D}-\mathbf{F})$, or $6(\mathbf{G}$ and $\mathbf{H})$ mice per group from at least 2 pooled, independent experiments. ${ }^{*} P<0.05$, ${ }^{* *} P<0.01$ and ${ }^{* * *} P<0.001$, relative to B6 controls $(\mathbf{A}-\mathbf{F})$ by 1-way ANOVA.

as IL-18 levels in serum 24 hours after challenge with Mtb H37Rv. Recipient mice reconstituted with $I l 18^{-/-} \mathrm{BM}$ secreted significantly less IL-18 and IFN- $\gamma$ compared with that observed in mice reconstituted with WT BM (Figure 5, A, B, and G, and Supplemental Figure 5, A and B), showing that a BM-derived cell type produces IL-18. CD11 $\mathrm{c}^{+}$cells have been suggested to rapidly produce IL-18 upon pathogen encounter (21). To determine whether CD11 $\mathrm{c}^{+}$cells are required for rapid IL-18 secretion in response to $M t b$, we generated straight and mixed BM chimeras using the CD11cDTR mouse model, which allows for specific depletion of CD11 $\mathrm{c}^{+}$cells with diphtheria toxin (DTX) (Supplemental Figure 5, G and H). When CD11cDTR chimeras were treated with DTX, secretion of both IL-18 and IFN- $\gamma$ was significantly reduced (Figure 5, C and D, and Supplemental Figure 5, C and D), suggesting an important role for CD11 $\mathrm{c}^{+}$cells. To determine whether CD11 $\mathrm{c}^{+}$cell-produced IL-18 is essential for rapid IFN- $\gamma$ secretion, mixed $I l 18^{-/ /} /$CD11cDTR chimeras were compared with WT/CD11cDTR chimeras. In this system, IL-18-producing CD11 $\mathrm{c}^{+}$cells can be selectively depleted without affecting other IL-18-producing hematopoietic cell types. DTX-treated Il18 $8^{-/} /$CD11cDTR chimeras did not produce IL-18 or IFN- $\gamma$ upon $M t b$ challenge, whereas WT/CD11cDTR chimeras did, revealing a critical role for CD11c cells as the source of IL-18 (Figure 5, E-G, and Supplemental Figure 4, E and F).

To determine whether $\mathrm{CD} 11 \mathrm{c}^{+}$cell types also take up $M t b$ within 24 hours, we used $M t b$-GFP and tracked bacterial uptake by different immune cell subsets. Splenic CD11 ${ }^{+}$cell types comprised half of all GFP-expressing $M t b$ after i.v. injection (Figure $5 \mathrm{H}$ ), and lung CD11 $\mathrm{c}^{+}$cells were the second-most infected cell type after i.t. $M t b$-GFP administration (Supplemental Figure 5I). In the spleen, almost all CD11 $\mathrm{c}^{+}$cells are DCs. A more detailed characterization of splenic DC subsets revealed a preferential uptake of $M t b$-GFP by $\mathrm{CD}^{+}$and $\mathrm{CD} 4^{-} \mathrm{CD} 8^{-}$(DN) DC subsets (Figure 5I). These results not only demonstrate a crucial role for $\mathrm{CD} 11 \mathrm{c}^{+}$cells in the secretion of IL-18 after $M t b$ exposure, but also suggest that $\mathrm{CD}^{+}$and DN DC subsets should be exploited as potential targets to induce IL-18-dependent immune defense mechanisms.

$I L-18$ is required for early noncognate protection against $M t b-$ induced disease. To address whether the early defense against TB mediated by noncognate sources of IFN- $\gamma$ (Figure 1) also depends on IL-18, Rag1 $1^{-/-}$mice (NK cells) and $\mathrm{Rag}^{-/-} \mathrm{Il} 2 \mathrm{rg}^{-/-}$mice that had received OT-ITg cells 4 weeks earlier (noncognate memory CD8 ${ }^{+}$ T cells) were infected with $M t b$ and subsequently treated with neu- 
A
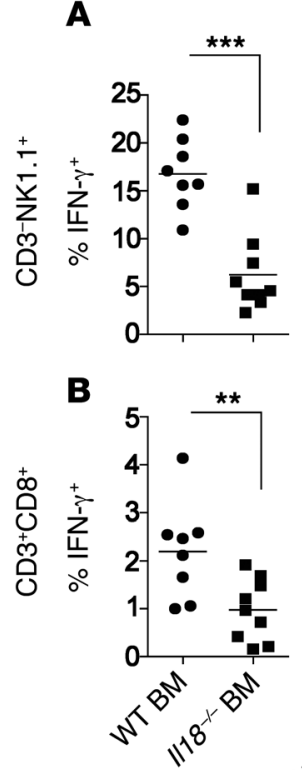

c

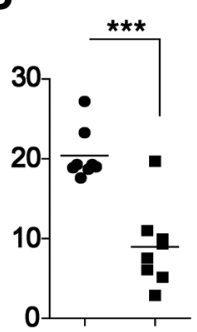

\section{D}

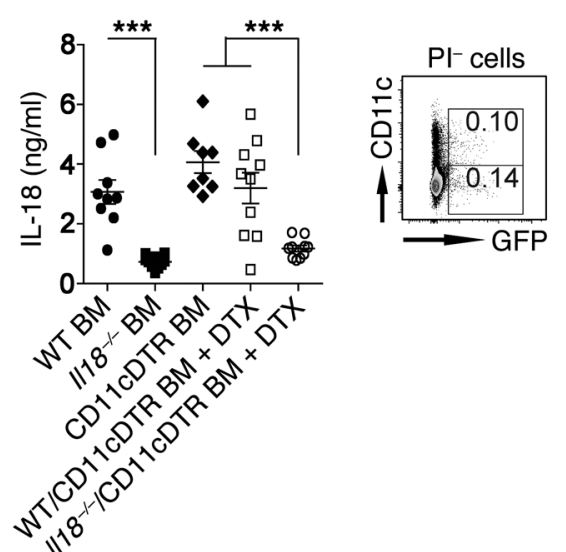

E

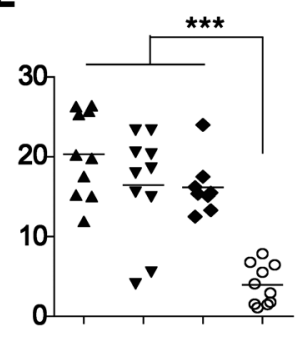

G

H

$\mathbf{F}$

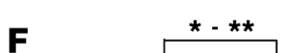

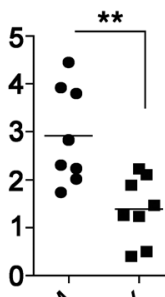

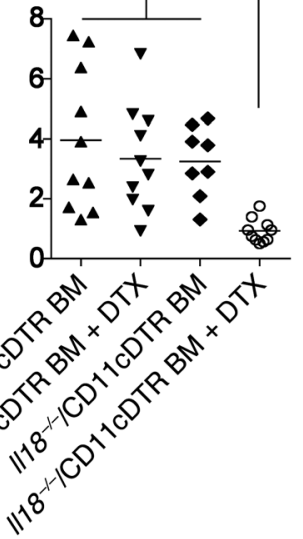

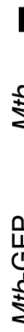

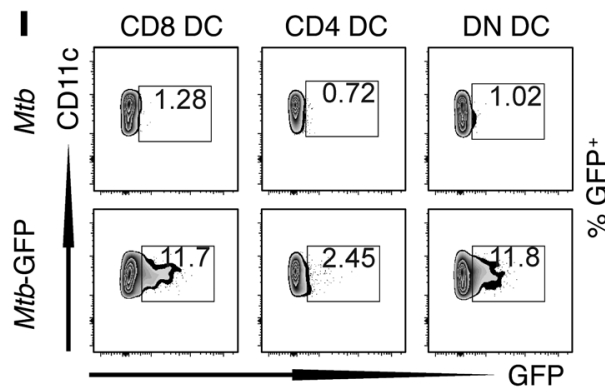

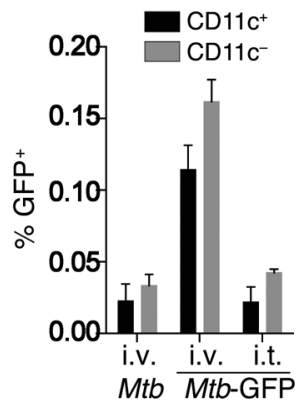

Figure 5. A BM-derived CD11c $\mathbf{c}^{+}$cell population is required for IL-18 secretion in response to $\mathbf{M t b}$. (A-C) Percentage of IFN- $\gamma^{+}$cells among total lung CD3-NK1.1 $(\mathbf{A}, \mathbf{C}$, and $\mathbf{E})$ and $\mathrm{CDB}^{+} \mathrm{CD} 8^{+}$(B, D, and $\left.\mathbf{F}\right)$ cells and serum IL-18 levels (C) of straight WT or I118-- (A and B) and CD11cDTR BM chimeras (C and D) as well as DTXand PBS-treated CD11CDTR mixed BM chimeras (E and F) 24 hours after injection of $1 \times 10^{8}$ CFU Mtb H37Rv. (H) Percentage of GFP+ cells among total viable splenocytes 24 hours after i.v. or i.t. injection of $1 \times 10^{8}$ CFU Mtb H37Rv or Mtb H37Rv-GFP into naive B6 mice. (I) Uptake of Mtb H37Rv-CFP by individual

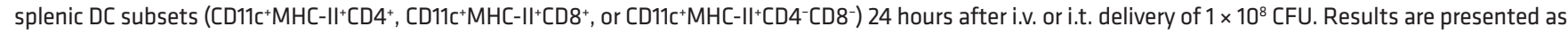
individual data points (A-G) or as pooled data (mean \pm SEM) and representative FACS plots (H and I) of 8 to 10 (A-G) or 4 to 6 (H and $\mathbf{I})$ mice per group from 2 (H and I) or $3(\mathbf{A}-\mathbf{C})$ pooled, independent experiments. ${ }^{*} P<0.05,{ }^{* *} P<0.01,{ }^{* * *} P<0.001$, by 1-way ANOVA. Mtb-GFP, Mtb H37Rv-GFP; PI, propidium iodide.

tralizing anti-IL-18 or control Ab. In both settings, anti-IL-18 treatment reversed the protective phenotype; mean survival in Rag1/mice was reduced from 49 days for control mice to 39 days for mice treated with anti-IL-18 (Figure 6A). Very similar results were obtained with $\mathrm{Rag}^{-/-} \mathrm{Il} 2 \mathrm{rg}^{-/-}$mice harboring memory OT-ITg cells. Whereas all $\mathrm{Rag}^{-/-} \mathrm{Il} 2 \mathrm{rg}^{-/-}$mice treated with anti-IL-18 succumbed to infection by day 35 , animals treated with control IgG showed no signs of disease by this time point, and $50 \%$ of mice survived past day 60 (Figure 7A). Furthermore, anti-IL-18 treatment significantly increased bacterial numbers in spleen and lung (Figure 6, B and C, and Figure 7, B and C), significantly exacerbated lung pathology, with large clusters of cell infiltrates (Figure 6, D and E, and Figure 7, D and E), and elevated the abundance of proinflammatory cytokines such as TNF- $\alpha$, IL-6, and IL- $1 \beta$ (Figure 6 F and Figure 7F). Additionally, despite an increase in bacterial numbers and cell infiltration, anti-IL-18 administration reduced iNOS expression in lung tissue compared with that detected in untreated or control IgGtreated animals (Figure 6D and Figure 7D), indicating that antiIL-18 treatment had a detrimental impact on effector mechanisms downstream of IFN- $\gamma$. Taken together, these results substantiate that IL-18 drives early IFN- $\gamma$-mediated defense against TB by NK cells and $M t b$-unrelated memory $\mathrm{CD}^{+} \mathrm{T}$ cells.

ESAT-6-dependent cytosolic contact improves vaccine-induced protection. To finally investigate whether ESAT-6-mediated cytosolic contact and subsequent IL-18-mediated IFN- $\gamma$ secretion could potentially be exploited for improved TB intervention strategies, we performed exploratory BCG vaccination experiments. It was recently demonstrated that rapid, cytokine-driven IFN- $\gamma$ secretion by memory $\mathrm{CD} 8^{+} \mathrm{T}$ cells instructs innate cells to become more potent effector cells, thereby significantly affecting the magnitude of the secondary recall response after primary L. monocytogenes infection (31). Given that in our model, i.v. exposure of mice with RD1-containing mycobacteria generated the strongest, most ubiquitous and rapid systemic IFN- $\gamma$ response (Figures 2 and 3), B6 mice were vaccinated via the i.v. route with a high dose of BCG, BCG::RD1, or BCG::RD1 ESAT-6 $\Delta 92-95$. After 60 days, mice were aerosol challenged with $M t b$ H37Rv (Figure 8A). Only i.v. vaccination with BCG::RD1, but not BCG::RD1 ESAT-6 $\Delta 92-95$, significantly improved protection against the $M t b$ challenge compared with vaccination with BCG (Figure 8, B and C). Considering that all vaccine strains induced a similar cytokine milieu after $M t b$ challenge (Figure $8 \mathrm{C}$ ) and that BCG::RD1 ESAT- $6 \Delta 92-95$ still contains all of the key protective ESAT- 6 T cell epitopes (57), these findings strongly suggest that ESAT-6-mediated cytosolic translocation and subsequent innate IFN- $\gamma$ secretion positively impact TB vaccine efficacy. Further work will have to clarify to what extent these findings depend on the ESAT-6-mediated IL-18 secretion described in this study and 
A
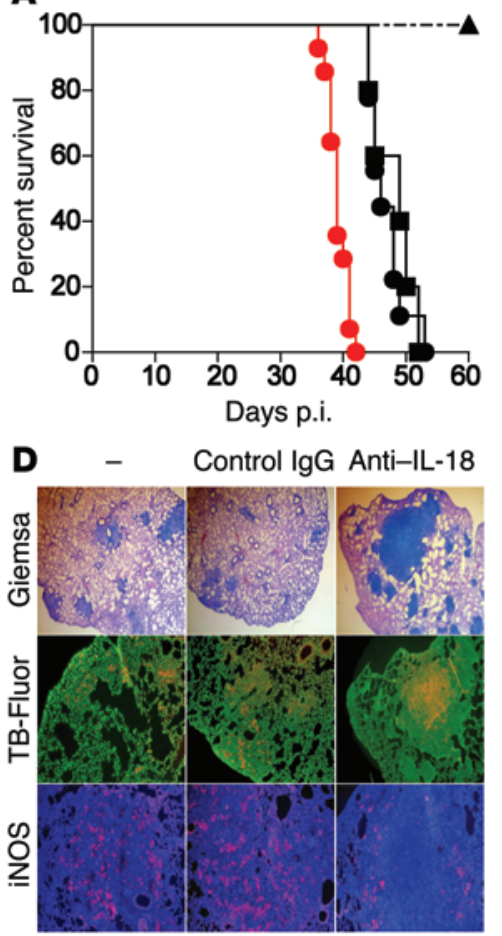

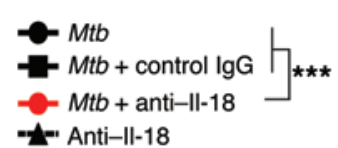

E

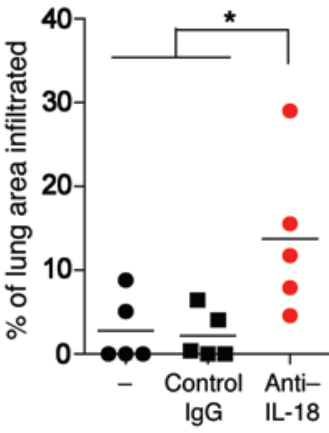

B
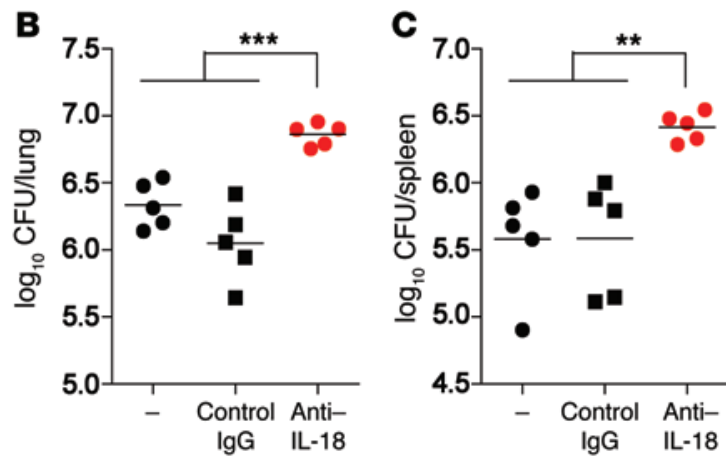

F

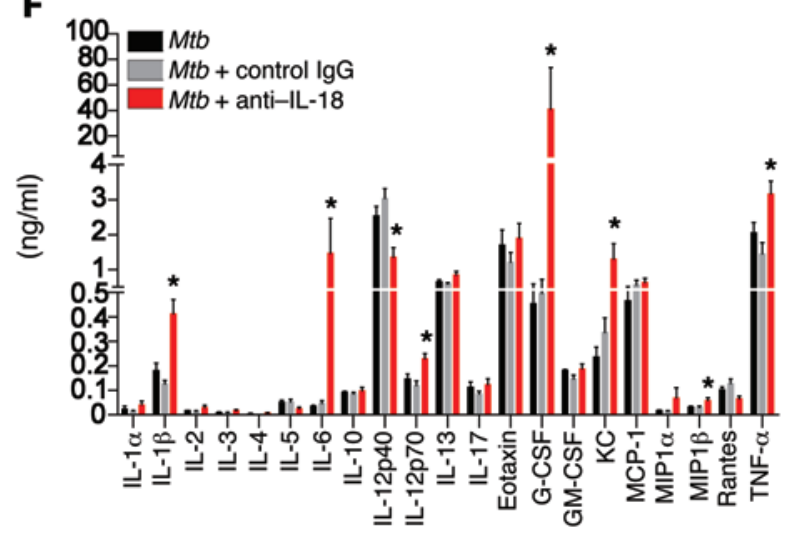

Figure 6. Early control of $\mathbf{M t b}$ infection by NK cells depends on IL-18. Rag1/- mice were infected with 200 CFU Mtb H37Rv via the aerosol route and treated weekly with either anti-IL-18 Ab or control IgG or were left untreated. As an additional control, naive Rag1/- mice were treated with anti-IL-18 Ab. Long-term survival (A), CFU in lung and spleen (B and C), a cytokine profile (F), as well as cell infiltrates (D and E) and iNOS expression in lung tissue (D) were assessed 34 days p.i. Results are presented as individual data points (B, C, and E), pooled data (mean \pm SEM) (F), and representative images (D) of 6 (A) or 5 (B-F) mice per group from 2 pooled independent experiments. ${ }^{*} P<0.05,{ }^{*} P<0.01$, and ${ }^{* * *} P<0.001$, by log-rank (Mantel-Cox) test (A), 1-way ANOVA (B, C, and E), and 1-way ANOVA for each cytokine (F). Original magnification, $\times 25$ (Giemsa), $\times 50$ (TB-Fluor), $\times 100$ (iNOS). G-CSF, granulocyte-CSF; GM-CSF, granulocyte macrophage-CSF.

whether ESAT-6-mediated cytosolic translocation can be uncoupled from the detrimental aspects of RD1.

\section{Discussion}

Our study provides compelling evidence for a protective role of noncognate lymphocytic sources of IFN- $\gamma$ in TB. We demonstrate that memory $\mathrm{CD}^{+} \mathrm{T}$ cells with an unrelated specificity as well as NK cells protect against acute TB via IL-18-dependent IFN- $\gamma$ secretion. Furthermore, we provide a comprehensive mechanistic framework for how IL-18-dependent innate IFN- $\gamma$ is produced in response to $M t b$, including a crucial role for bacterial viability, ESAT-6-dependent cytosolic contact, and NLRP3 activation (Figure 9). The observations that both memory CD8 ${ }^{+}$ T cells and NK cells can act as the sole source of host-protective IFN- $\gamma$ during $M t b$ infection highlight the redundancy in the source of IFN- $\gamma$ during early $M t b$ infection and reveal a previously unappreciated level of functional interchangeability between IL-12 (33) and IL-18 during Mtb infection. Considering that (a) IFN- $\gamma$ can orchestrate host innate immune responses and has an impact on the magnitude of recall responses (31) and that (b) IL-18 has beneficial effects on antigen-specific T cell responses (58), induction of host-pathogen interactions that lead to rapid, IL-18-dependent IFN- $\gamma$ secretion should be a crucial feature of improved TB intervention strategies.
The efficacy of subunit protein vaccines is dependent on the right choice of adjuvants (59), which activate appropriate PRRs such as TLRs $(60,61)$. In contrast, live attenuated vaccines rarely require adjuvants, as some of the ligands involved in adjuvanticity are already contained in the live vaccine (62). With a more detailed understanding of ligand-PRR interactions and the resulting immune responses of vaccine strains, a more targeted design of recombinant live vaccines becomes feasible. In line with this, we have recently elucidated that activation of the AIM2 inflammasome contributes to the superior protection afforded by a recombinant BCG strain compared with that seen with conventional BCG vaccination (63). Here, we show that rapid IL-18 secretion that significantly contributes to early protective immunity against TB depends on ESAT-6-mediated NLRP3, but not AIM2, inflammasome activation. Incorporating NLRP3 inflammasomebased mechanisms that lead to innate IFN- $\gamma$ production by nonspecific memory CD8 ${ }^{+} \mathrm{T}$ cells and NK cells should, therefore, also be taken into consideration for future TB vaccine improvement.

Our study also shows that NLRP3 activation in response to $M t b$ depends on RD1-mediated and ESAT-6-dependent cytosolic contact, a feature that is incorporated in the recombinant BCG strain BCG::RD1 (43). However, because of increased virulence in immunocompromised hosts as well as prolonged persistence in fully immune-competent hosts, BCG::RD1 has been deemed 
A

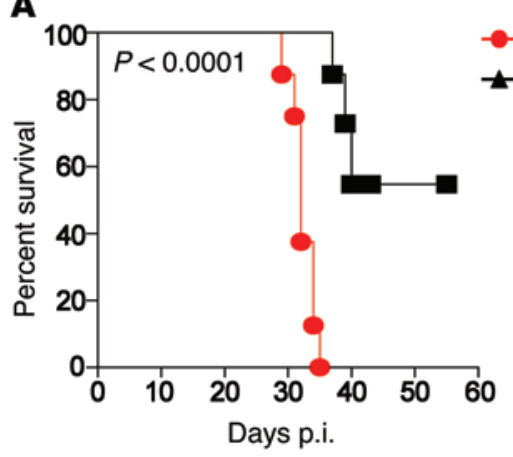

D Control IgG Anti-IL-18

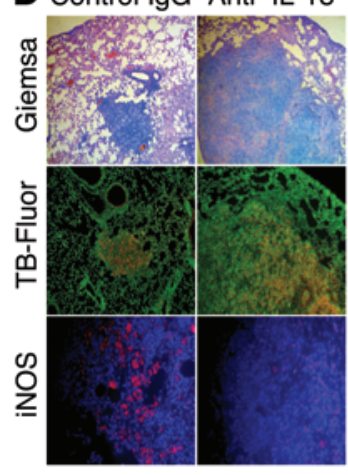

OT-ITg + anti-IL-18

$\mathrm{OT}-\mathrm{ITg}+$ control IgG

$\mathbf{E}$

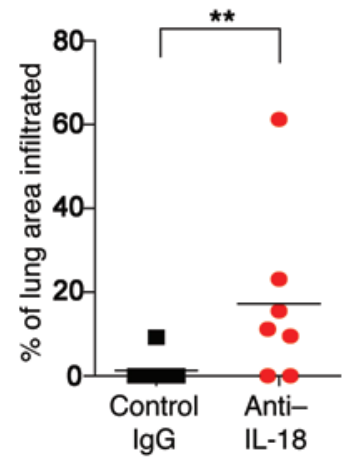

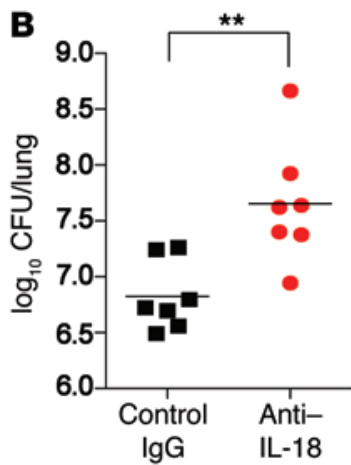

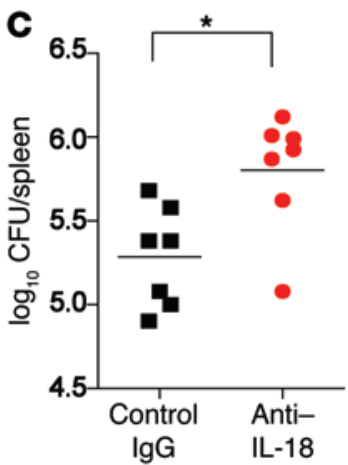

$\mathbf{F}$

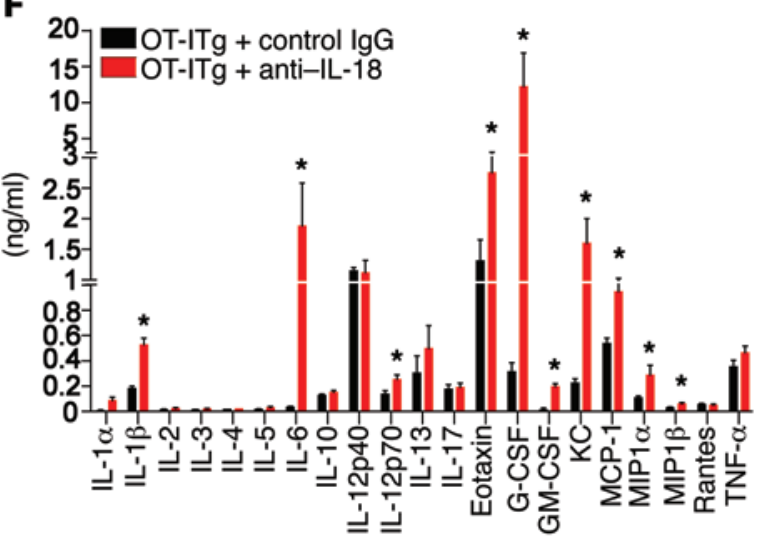

Figure 7. Early control of $\mathbf{M t b}$ infection by noncognate memory $\mathrm{CDB}^{+} \mathbf{T}$ cells depends on IL-18. $\mathrm{Rag}^{-1-} \mid I 2 \mathrm{rg}^{-/-}$mice that had received OT-ITg cells 4 weeks earlier were infected with 200 CFU Mtb H37Rv via the aerosol route and treated weekly with either anti-IL-18 Ab or control IgG. Long-term survival (A), CFU in lung and spleen (B and $\mathbf{C}$ ), a cytokine profile (F), as well as cell infiltrates ( $\mathbf{D}$ and $\mathbf{E}$ ) and iNOS expression in lung tissue (D) were assessed 27 days p.i. Results are presented as individual data points (B, C, and E), pooled data (mean \pm SEM) (F), and representative images (D) of 12 (A) or 7 (B-F) mice per group from 2 pooled, independent experiments. ${ }^{*} P<0.05$ and ${ }^{* *} P<0.01$ by log-rank (Mantel-Cox) test (A), unpaired, 2 -tailed Student's $t$ test (B, C, and E), and 1-way ANOVA for each cytokine (F). Original magnification, ×50 (Giemsa), ×100 (TB-Fluor), ×200 (iNOS).

an unsuitable human vaccine candidate, despite increased systemic protection over BCG against $M t b$ challenge $(43,64)$. To combine enhanced protection with decreased virulence, a panel of BCG::RD1 strains with distinct aa changes in the es $x A$ gene were recently evaluated as vaccine candidates (65). Some of these strains showed high protective capacity with low virulence in both mouse and guinea pig models (65). These observations suggest that a fine-tuned balance needs to be found between inducing protective immune responses and limiting virulence. While a complete loss of biological activity of ESAT- 6 may lead to decreased virulence, but not to improved vaccine-induced protection $(44,47$, $64,66)$, targeted aa substitutions that only affect the stability of ESAT- 6 may combine both effects $(65,66)$. Overall, these results indicate that a detailed understanding of immune responses stimulated by different vaccine candidates in a spatiotemporal framework may be used to design a next-generation live, recombinant vaccine against $\mathrm{TB}$ that combines beneficial features of several of the current vaccine candidates.

While recombinant ESAT- 6 is sufficient to activate the NLRP3 inflammasome in macrophages in vitro (55), our study suggests that in vivo cytosolic NLRP3 activation depends on active ESAT-6 secretion by viable $M t b$ and the immune architecture. In particular, $\mathrm{CD} 8^{+}$and DN CD11 $\mathrm{c}^{+} \mathrm{DCs}$ appear to be required for rapid $\mathrm{Mtb}$ uptake and subsequent IL-18 secretion in the spleen. This is in line with observations made during Salmonella infections, in which rapid NLRC4 inflammasome activation occurred predominantly in $\mathrm{CD}^{+}$DCs (21) and, additionally, emphasizes the substantial differences between BM-derived myeloid cell populations and bona fide DCs found in vivo (67). Human equivalents of mouse $\mathrm{CD} 8^{+}$DCs have been identified as XCR1 $1^{+} \mathrm{CD} 141^{+}$cells (68), and there is increasing evidence that most mouse DC subsets have a human phenotypic and functional equivalent (69). In addition, studies of other pathogens have identified murine $\mathrm{Ly} 6 \mathrm{C}^{+} \mathrm{CCR} 2^{+}$ inflammatory monocytes as sensor cells for L. monocytogenes infection (23) and subcapsular sinus macrophages as sensor cells for $P$. aeruginosa infection (22), resulting in the release of IL-18 and the subsequent production of IFN- $\gamma$ by innate cell types. These discrepancies highlight the need to investigate the mechanistic framework underlying noncognate IFN- $\gamma$ production independently for different pathogens. In particular, identifying which antigen-presenting cell (APC) subset is most efficient at sensing a specific class of pathogens in vivo remains critical. Because of the diverse expression of different internalization receptors and the abundance of inflammasome components, various myeloid cells are endowed with unique abilities to interact with $M t b$. In this context, characterization of the myeloid cell population, which produces IL-18 in an NLRP3-dependent manner (CD8 ${ }^{+}$and DN DCs capable of cross-presentation), will foster innovative strategies for ESAT-6-mediated NLRP3 activation. Our study provides a complete mechanistic framework for noncognate in vivo 
B

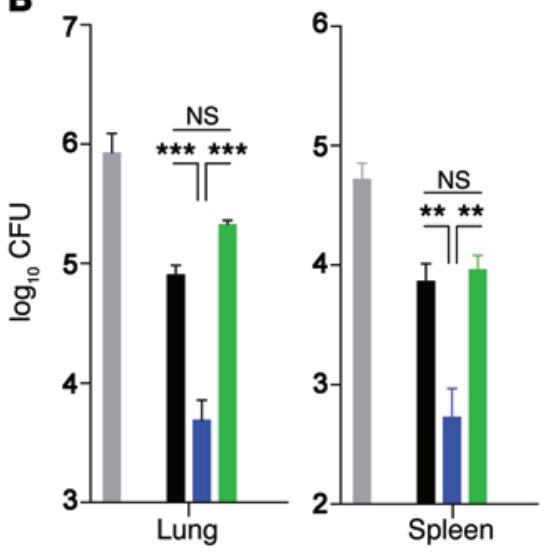

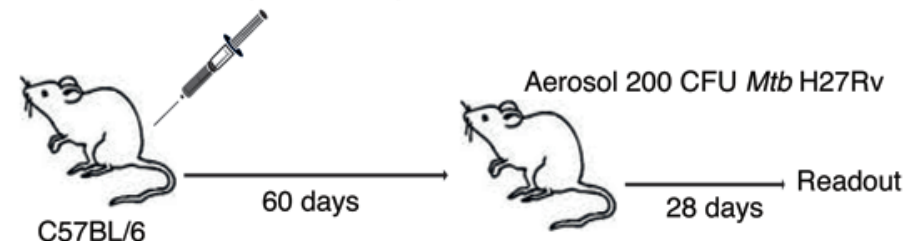

C

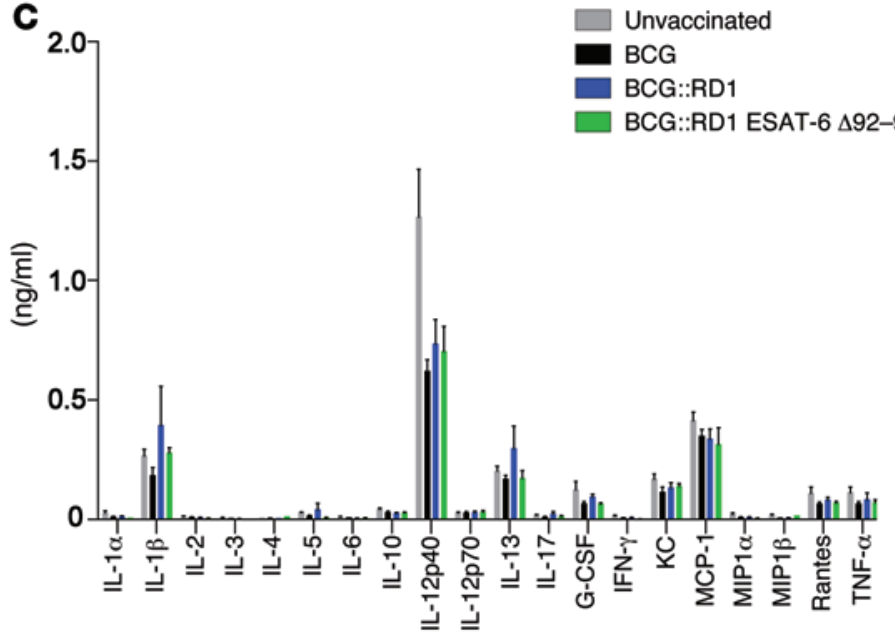

Figure 8. Cytosolic contact of ESAT-6 improves vaccine-induced protection. (A) B6 mice were vaccinated i.v. with $1 \times 10^{7}$ CFU BCG, BCG::RD1, or BCG::RD1 ESAT-6 $\Delta$ 92-95. Sixty days later, mice were aerosol infected with 200 CFU Mtb H37Rv. Twenty-eight days p.i., mice were sacrificed, and CFU in spleen and lung (B) as well as serum cytokines (C) were assessed. Results are presented as pooled data (mean \pm SEM) of 6 mice per group from 2 pooled, independent experiments. ${ }^{* *} P<0.01$ and ${ }^{* *} P<0.001$, by 1-way ANOVA (B).

protection against an intracellular pathogen. We have identified the activating mycobacterial factor, the sensing APC subset, and the cytosolic NLR molecule. Although cytosolic egress (70) and ESAT-6-dependent phagosomal destabilization (71) have been described for macrophages and DCs, this is the first study to our knowledge to link inflammasome activation and IL-18 release in the context of adaptive immunity in TB. We consider the identification of ESAT-6-dependent activation of NLRP3 in a bona fide DC subset in vivo a significant step forward in the development of innovative $\mathrm{T}$ cell therapies.

In line with these observations, our data emphasize that the route of mycobacterial exposure has a profound impact on IL-18dependent IFN- $\gamma$ production as well as on protection against $M t b$ challenge after vaccination. Whereas i.v. infection with $M t b$ resulted in up to $6 \mathrm{ng} / \mathrm{ml} \mathrm{IL}-18$, i.t. administration only yielded up to $1 \mathrm{ng} / \mathrm{ml} \mathrm{IL-18,} \mathrm{confirming} \mathrm{that} \mathrm{IL-18} \mathrm{levels} \mathrm{directly} \mathrm{correlate}$ with the amount of IFN- $\gamma$ being produced by memory CD8 ${ }^{+} \mathrm{T}$ cells and NK cells (21). There are several factors that could explain why i.t. infection induces lower IL-18 secretion: (a) the lower number of DCs in the lung compared with numbers in the spleen; (b) the slower access of $M t b$ to the bloodstream and therefore to distant CD11 $\mathrm{c}^{+}$cells; and (c) the organ-specific differences in regulatory mechanisms. Although i.v. administration of a vaccine may be unpopular, it is interesting to note that malaria vaccine trials using irradiated sporozoites only showed protection after i.v. vaccination (72). Strategic location of APC subsets within the tissue as well as proximity to IL-18-responsive cell types appear to be crucial features, dictating not only the effectiveness of the early immune response but also of the secondary recall of immunity.
Therefore, determining which human APC subset in different tissues is the most efficient one for sensing ESAT- 6 might enable the development of improved strategies aimed at the targeted delivery of TB vaccines to a particular APC subset $(73,74)$ and lead to optimal and localized IL-18-mediated IFN- $\gamma$ secretion.

Another critical question arises from our study: how does ESAT-6 activate NLRP3 in vivo? Restriction of phagosomal acidification was shown to be a crucial prerequisite for ESX-1-dependent phagosomal rupture and rapid cytosolic contact in vivo (71). Although ESAT- 6 is known for its membrane-damaging capabilities, direct activation of the NLRP3 inflammasome through ESAT-6-mediated translocation of $M t b$ components into the cytosol cannot be excluded. Assembly of NLRP3 inflammasomes requires cytosolic sensing of danger signals or activation through specific surface receptors (26). At least 4 models for NLRP3 activation exist: the lysosomal rupture model; the pore formation model; the ROS model; and the $\mathrm{K}^{+}$efflux model (75). To date, these models have not been experimentally proven or disproven. Furthermore, increasing evidence suggests that direct access of the NLRP3-activating agent to the cytosol may not be required, because "tickling" of the DC surface with alum also appears to initiate NLR activation (76). These observations suggest a possible role for interactions with surface or endosomal receptors and warrant further investigation into the possibility of cross-linking antigens to specific ligands for surface receptors of distinct DC subsets such as XCR1, SIGN, DEC205, or CLEC9A. Further research will be required to determine the processes involved in the transfer of $M t b$ pathogenassociated molecular patterns (PAMPs) from the phagosome into the cytosol and to what extent soluble $\mathrm{N}$-ethylmaleimide-sensi- 


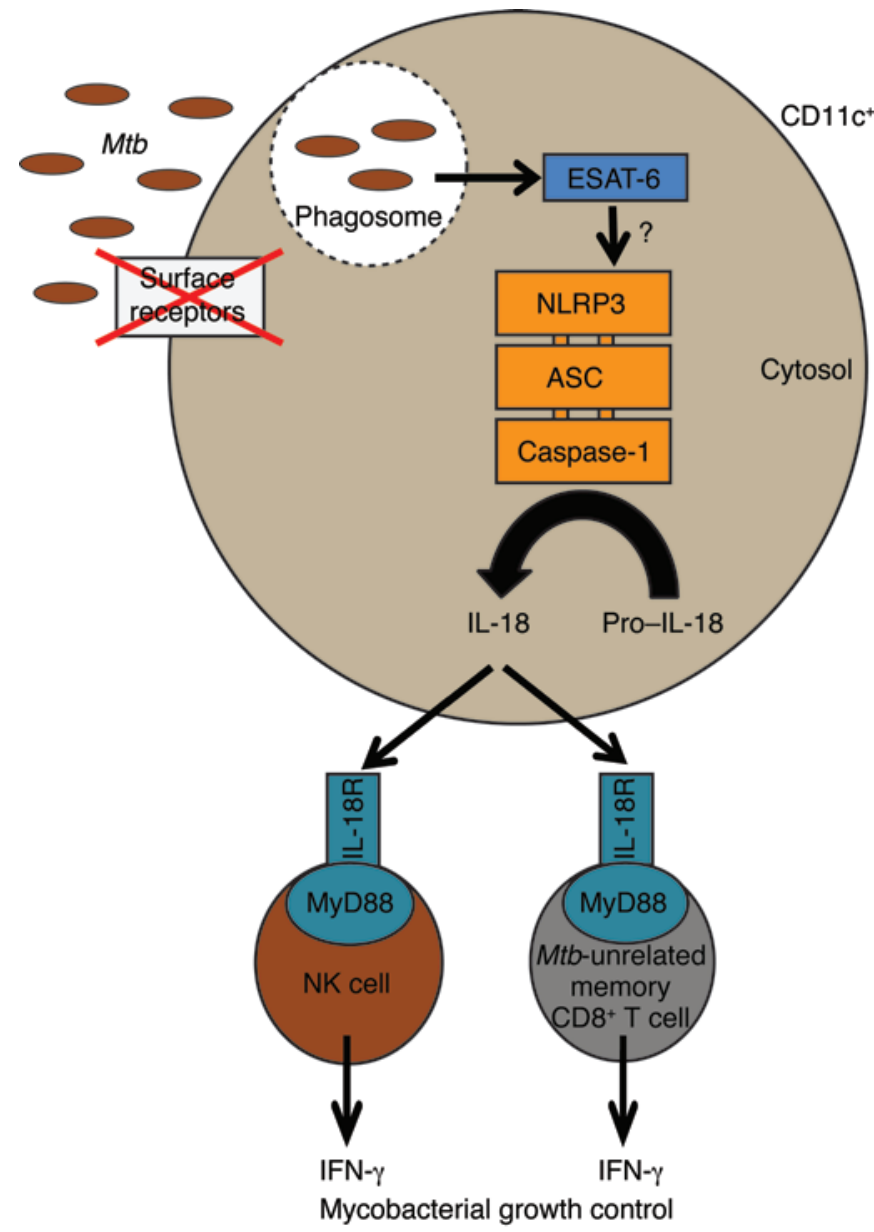

tive factor attachment receptor (SNARE) proteins such as Sec22B and Sec61 $(77,78)$ are involved in such transfers.

On the other hand, NLRP3 activation also needs to be controlled tightly, because hyper-activation or gain-of-function mutations can result in excessive inflammation, autoinflammatory syndromes, or metabolic disorders (79). Detrimental aspects of NLRP3 activation are often linked to excessive production of IL-1 $\beta$. Whether IL-18 secretion can be uncoupled from IL-1 $\beta$ production is not entirely clear. IL-1 $\beta$ secretion requires a priming signal that leads to transcriptional activation of pro-IL-1 $\beta$ synthesis (26), whereas pro-IL-18 is considered to be preformed. Although our findings demonstrate that ESAT-6-mediated IL-18 secretion does not depend on TLR- or IFN-dependent priming signals, it appears unlikely that a strategy aimed at activating NLRP3 without prior activation of priming signaling pathways can be achieved using a live whole-cell vaccine. Furthermore, it may be important to consider existing mutations in inflammasome pathways that may compromise the effectiveness of a vaccine. The effect of NLRP3 mutations on autoinflammatory and other diseases (80, 81) is well documented. These considerations will be critical in order to maximize the potential of personalized medicine targeted at patient cohorts for which current intervention strategies might be ineffective or fatal. For example, in order to potentially harness the host-directed therapeutic effects from IL-18-dependent IFN- $\gamma$ production, it could also be beneficial to both activate IL-18responsive cell types and boost cell numbers. IL-2-anti-IL-2 and
Figure 9. ESAT-6-dependent cytosolic pattern recognition drives noncognate TB control in vivo. Model depicting the mechanistic framework underlying mycobacterial growth control by noncognate sources of IFN- $\gamma$. Cytosolic translocation of ESAT- 6 activates the NLRP3 inflammasome by a yet-to-be-defined mechanism within CD11c ${ }^{+}$cells. Subsequent secretion of IL-18 drives the secretion of host-protective IFN- $\gamma$ by Mtb-unrelated memory CD8 ${ }^{+} T$ cells and NK cells.

IL-15-IL-15R $\alpha$ Fc complexes have been shown to boost NK cell and memory $\mathrm{CD} 8^{+} \mathrm{T}$ cell numbers and enhance their killing capacity (82). In certain instances, the therapeutic potential of IL-15 and/ or IL-2 transpresentation may prove to be a very effective way of activating and boosting noncognate cell activity, particularly in the absence of $\mathrm{CD} 4^{+} \mathrm{T}$ cells.

In summary, our findings: (a) demonstrate a role for $M t b-$ unrelated immune cells in IFN- $\gamma$-mediated protection against TB; (b) delineate the mechanistic framework for the production of IL-18-dependent production of IFN- $\gamma$ by such noncognate cells; and (c) provide initial exploratory results suggesting that IL-18responsive cell types are potential targets for preventive intervention. Considering that rapid, IL-18-dependent IFN- $\gamma$ responses are not evoked by current first- and second-generation TB vaccine candidates, we believe that this has critical implications for the future design of vaccines and host-directed therapy in TB.

\section{Methods}

Mice. C57BL/6J and C57BL/6N mice were purchased from Charles River Laboratories. The following $\mathrm{KO}$ and $\mathrm{Tg}$ mouse strains were used:

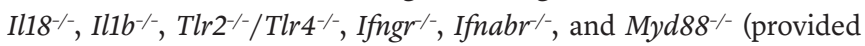
by B. Raupach, Max Planck Institute for Infection Biology [MPIIB], Berlin, Germany); Nlrp3 $3^{-/}$(provided by J. Tschopp, University of Lausanne, Lausanne, Switzerland); caspase-1/-/, caspase- $11^{-/}$, caspase- $1^{-/-}$

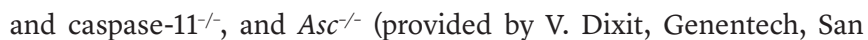
Francisco, California, USA); 129S2/SvPas (provided by R. Kemler, Max Planck Institute for Immunobiology and Epigenetics [MPI-IE],

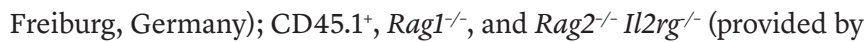
F. Melchers, MPIIB, Berlin, Germany); OT-ITg (from The Jackson Laboratory); Sting ${ }^{-/-}$(provided by Lei Jin, Albany Medical College, Albany, New York, USA); Aim2 ${ }^{-/-}$(83) (provided by V. Hornung, University of Bonn, Bonn, Germany); CD11cDTR (provided by H.D. Chang, German Rheumatism Research Center [DRFZ], Berlin, Germany); and Ifng $^{-/}$and P14 LCMV $\mathrm{gp} 33-41_{1}$ TCRtg (provided by M. Löhning, DRFZ, Berlin, Germany ). All mice were bred and maintained at the MPIIB, the Research Institutes for Experimental Medicine (FEM) Charité, and the DRFZ (all located in Berlin, Germany). For infection experiments, all mice were sex and age matched and kept in our biosafety level facility (BSL 3) under specific pathogen-free (SPF) conditions.

Bacterial strains and infection of mice. All Mtb and BCG strains were grown in Middlebrook 7H9 broth (BD Biosciences) supplemented with $0.2 \%$ glycerol, $0.05 \%$ Tween- 80 , and $10 \%$ albumin dextrose catalase (ADC) enrichment (BD Biosciences) and appropriate antibiotics if necessary. The Mtb strain H37Rv $\triangle$ ESAT- 6 was provided by D. Sherman (University of Washington, Seattle, Washington, USA). Recombinant BCG::RD1 strains and derivatives were constructed as described previously (65). Stm SL1344 was grown overnight at $37^{\circ} \mathrm{C}$ with shaking in Luria Bertani broth. Midlogarithmic cultures of all strains were harvested, washed in $\mathrm{PBS}$, and stored at $-80^{\circ} \mathrm{C}$. For all short-term assays, 
mice were infected i.v., i.t., s.c., or i.d. with different doses of bacteria (as indicated in the figure legends) in a volume of 50 to $200 \mu \mathrm{l}$. For aerosol infection, animals were exposed to a dose of approximately $200 \mathrm{CFU} M t b /$ mouse, using a Glas-Col inhalation exposure system. At designated time points, serial dilutions of tissue homogenates were plated onto Middlebrook 7H11 agar supplemented with 10\% Middlebrook oleic albumin dextrose catalase (OADC) Enrichment (BD Biosciences), ampicillin $(25 \mu \mathrm{g} / \mathrm{ml})$, and appropriate additional antibiotics if necessary. CFU were determined after 3 to 4 weeks of incubation at $37^{\circ} \mathrm{C}$. For survival experiments, mice were sacrificed when a moribund state was reached. Death was never used as an endpoint.

Vaccinations. C57BL/6 mice were vaccinated with BCG, BCG::RD1, or BCG::RD1 ESAT-6 $\Delta 92-95$ i.v. in the lateral tail vein with $1 \times 10^{7} \mathrm{CFU}$ in a volume of $200 \mu$ l. Sixty days after vaccination, mice were challenged with $200 \mathrm{CFU} M t b \mathrm{H} 37 \mathrm{Rv}$ via the aerosol route. At designated time points, spleen and lung were removed aseptically, homogenized in PBS with 0.05\% Tween-80, and plated in serial dilutions onto 7H11 agar containing 2-thiophenecarboxylic acid hydride (TCH) (84) to prevent BCG growth.

Heat inactivation of bacteria. For heat inactivation, bacteria were grown as described above, enumerated, and washed twice with PBS before incubation at $65^{\circ} \mathrm{C}$ in a water bath for 1 hour. Effective killing was verified by plating heat-killed bacteria onto appropriate agar plates.

Isolation of lung leukocytes. Lungs were perfused with PBS, extracted, mechanically disrupted, and digested via incubation for 30 minutes with RPMI 1640 medium supplemented with glutamine, Na-pyruvate, 2-ME, penicillin, streptomycin, 10\% heat-inactivated FCS, collagenase D (Roche), and collagenase type VIII (SigmaAldrich). Subsequently, rbc-depleted, single-cell suspensions were prepared as described elsewhere.

$B M$ chimeric mice and selective depletion of DCs. BM chimeric mice were generated as described previously (21). Briefly, C57BL/6 mice were irradiated with 9 Gy and reconstituted with $5 \times 10^{6} \mathrm{~T}$ celldepleted BM cells from $I l 18^{-/}$, Tg CD11cDTR, or CD45.1 mice. For mixed BM chimeras, irradiated mice were reconstituted with a 1:1 mixture of BM from different mice. Chimeric mice were maintained for 6 weeks on drinking water containing enrofloxacin antibiotic (125 $\mathrm{mg} / \mathrm{l}$ ) and allowed to reconstitute for at least 8 weeks. Depletion of CD11 $c^{+}$cells was achieved by injecting CD11cDTR chimeric mice i.p. twice with 100 ng DTX 3 days and 1 day before the start of experiments. Effectiveness of depletion was checked by flow cytometry.

Assessment of ex vivo IFN- $\gamma$ secretion. Ex vivo IFN- $\gamma$ secretion by distinct lymphocyte subsets was assessed as described previously (21). Briefly, mice were injected i.v., i.t., s.c., or i.d. with different doses of bacteria (as described in the figure legends), heat-inactivated bacteria, or purified ligands (BEI Resources, National Institute of Allergy and Infectious Diseases [NIAID], NIH). At different time points (as described in the figure legends) after injection of bacteria, organs were aseptically removed, single-cell suspensions were prepared, and rbc were lysed. Cells $\left(1 \times 10^{6}\right)$ were stained with the Mouse IFN- $\gamma$ Secretion Assay Detection Kit (Miltenyi Biotec) according to the manufacturer's instructions, and IFN- $\gamma$ secretion was analyzed by flow cytometry.

Flow cytometry. To assess the expression of surface antigens and IFN- $\gamma$ secretion, viable, rbc-depleted single-cell suspensions were stained with mAbs (all from BD Pharmingen) against CD4 (clone GK1.5); CD8 $\alpha$ (clone 53-6.7); CD3 (clone 145-2C11); NK1.1 (clone PK136); CD45.1 (clone A20); CD45.2 (clone 104); CD49b (clone DX5);
$\beta$-TCR (clone H57-597); $\gamma \delta$-TCR (clone GL3); CD62L (clone MEL-14); CD44 (clone 1M7); CD90.1 (clone 30-H12); CD11b (clone M1/70); CD11c (clone HL3); MHC II (clone AF6-120.1); CD103 (clone 2E7); Ly6G (clone 1A8); F4/80 (clone BM8); TCR Vß Repertoire Kit (Beckman Coulter); or IFN- $\gamma$ detection Ab (Miltenyi Biotec), as described elsewhere (21). After washing the cells, samples were analyzed using a FACSCanto II or an LSR II flow cytometer (both from BD Biosciences). Propidium iodide $(2 \mu \mathrm{g} / \mathrm{ml})$ was added to exclude dead cells.

Histology and immunofluorescence. Lung lobes were collected aseptically, fixed overnight with $4 \% \mathrm{w} / \mathrm{v}$ paraformaldehyde, and embedded in paraffin. Tissues were cut at $2-\mu \mathrm{m}$ thickness and stained with Giemsa, TB Fluor (Merck), or anti-iNOS Ab (Thermo Scientific) according to standard protocols described elsewhere (28).

Isolation, enrichment, and in vitro expansion of NK cells. NK cells were negatively isolated from the spleens and LNs of donor mice using an NK cell enrichment kit and MACS Cell Separation Technology (Miltenyi Biotec) according to the manufacturer's instructions. Isolated and purified NK cells were cultured with recombinant human IL-2 (Peprotech) as described previously (85). The purity of cells after culture was determined by flow cytometry, and $1 \times 10^{6} \mathrm{NK}$ cells were adoptively transferred i.v. on days 5 and 6 after culture into naive $\mathrm{Rag}^{-/-} \mathrm{Il} 2 \mathrm{rg}^{-/}$mice.

Multiplex and ELISA. Blood for serum analysis was taken postmortem from the aorta abdominalis, collected in serum separator tubes (BD), and left for 30 minutes at room temperature, followed by centrifugation at $12,000 \times g$ for 3 minutes. Sera were stored at $-20^{\circ} \mathrm{C}$ until analysis. Measurements were performed using multiplex bead-based immunoassay kits (Bio-Rad) or ELISA (MBL) according to the manufacturer's instructions. Samples were acquired on a Bio-Rad instrument or a SpectraMax ELISA Reader (Molecular Devices).

Generation and transfer of Tg memory CD ${ }^{+}$T cells. Tg CD62L $\mathrm{L}^{\text {hi }}$ memory $\mathrm{CD}^{+} \mathrm{T}$ cells were prepared as described previously (36). In brief, splenocytes from Tg OT-I or P14 mice were incubated with SIINFEKL or KAVYNFATC peptide-coated irradiated syngeneic splenocytes, respectively, and cultured for 4 days at $37^{\circ} \mathrm{C}$. The activation of Tg cells was checked routinely by staining cells with anti-CD8 $\alpha$ (clone 53-6.7; BD); anti-V 22 (clone B20.1; BD); and anti-CD25 (clone PC61.5; BD) and analyzing by flow cytometry. Activated OT-ITg or P14Tg cells $\left(1 \times 10^{7}\right)$ were adoptively transferred into naive $\mathrm{Rag2}^{-/-} \mathrm{Il}_{2 \mathrm{rg}^{-/-}}$, Ifngr ${ }^{-/}$, or B6 recipients. Mice were aerosol infected with $M t b$ H37Rv 4 to 6 weeks later.

Abs. For cytokine neutralization, mAbs against IL-18 and IFN- $\gamma$ were produced and purified in-house from hybridomas using standard techniques (86). Neutralizing mouse IL-15 Ab was purchased from R\&D Systems. A total of $200 \mu \mathrm{g}$ anti-IL-18 (clone SK113AE4; provided by I. Förster, University of Bonn, Bonn, Germany); anti-IFN- $\gamma$ (clone XMG1.2); anti-IL-15 (catalog AF447; R\&D Systems); or control rat IgG was injected i.p. weekly in a volume of $200 \mu \mathrm{l}$.

Statistics. Flow cytometric data were analyzed using FlowJo software, and statistical analysis was performed using GraphPad Prism, version 5.04 (GraphPad Software). One-way ANOVA was followed by Bonferroni's multiple comparisons test for parametric samples, and unpaired, 2-tailed Student's $t$ tests were used. A $P$ value of less than 0.05 was considered significant.

Study approval. All animal experiments were conducted according to German animal protection laws and approved by the State Office for Health and Social Affairs Berlin (Landesamt für Gesundheit und Soziales Berlin; LAGeSo, T0087/13, G0031/13). 


\section{Author contributions}

AK and SHEK conceived the study. AK, UZ, and CP performed experiments. MS generated $\mathrm{mAbs}$. $\mathrm{AD}$ and $\mathrm{RB}$ provided reagents and intellectual input. AK performed data analysis and wrote the manuscript. SHEK commented extensively on the manuscript. All co-authors read and approved the final manuscript.

\section{Acknowledgments}

We thank B. Opitz and U. Schaible for providing bacteria and mice; N.C. Smith and A. Vogelzang for critical reading of the manuscript; and M.L. Grossman for editorial assistance. This work was supported by the Max Planck Society; the European Union's Seventh Framework Programme (EU FP7) "ADITEC" project
(HEALTH-F4-2011-280873); and the EU Horizon 2020 "TBVAC 2020 ” project (grant 643381), to S.H.E. Kaufman. R. Brosch also acknowledges support from EU grant 643381 and the Fondation pour la Recherche Médicale (DEQ20130326471). A. Kupz was supported by the National Health and Medical Research Council of Australia through a CJ Martin Biomedical Early Career Fellowship grant (APP1052764).

Address correspondence to: Stefan H.E. Kaufmann or Andreas Kupz, Max Plank Institute for Infection Biology, Charitéplatz 1, 10117, Berlin, Germany. Phone: 49.30.28460.500; E-mail: kaufmann@ mpiib-berlin.mpg.de. Phone: 49.30.28460.520; E-mail: kupz@ mpiib-berlin.mpg.de or andreas.kupz@jcu.edu.au.
1. Kaufmann SH, Evans TG, Hanekom WA. Tuberculosis vaccines: time for a global strategy. Sci Transl Med. 2015;7(276):276fs8.

2. World Health Organization. Global Tuberculosis Report 2015. Geneva, Switzerland: World Health Organization; 2015.

3. Nunes-Alves C, Booty MG, Carpenter SM, Jayaraman P, Rothchild AC, Behar SM. In search of a new paradigm for protective immunity to TB. Nat Rev Microbiol. 2014;12(4):289-299.

4. O'Garra A, Redford PS, McNab FW, Bloom CI, Wilkinson RJ, Berry MP. The immune response in tuberculosis. Annu Rev Immunol. 2013;31:475-527.

5. Cambier CJ, Falkow S, Ramakrishnan L. Host evasion and exploitation schemes of Mycobacterium tuberculosis. Cell. 2014;159(7):1497-1509.

6. Baena A, Porcelli SA. Evasion and subversion of antigen presentation by Mycobacterium tuberculosis. Tissue Antigens. 2009;74(3):189-204.

7. Srivastava S, Ernst JD. Cutting edge: Direct recognition of infected cells by CD4 $\mathrm{T}$ cells is required for control of intracellular Mycobacterium tuberculosis in vivo. JImmunol. 2013;191(3):1016-1020.

8. Gengenbacher M, Kaufmann SH. Mycobacterium tuberculosis: success through dormancy. FEMS Microbiol Rev. 2012;36(3):514-532.

9. Cooper AM. Cell-mediated immune responses in tuberculosis. Annu Rev Immunol. 2009;27:393-422.

10. MacMicking JD, North RJ, LaCourse R, Mudgett JS, Shah SK, Nathan CF. Identification of nitric oxide synthase as a protective locus against tuberculosis. Proc Natl Acad Sci U S A. 1997;94(10):5243-5248.

11. Flynn JL, Chan J, Triebold KJ, Dalton DK, Stewart $\mathrm{TA}$, Bloom BR. An essential role for interferon $\gamma$ in resistance to Mycobacterium tuberculosis infection. J Exp Med.1993;178(6):2249-2254.

12. Deffur A, Mulder NJ, Wilkinson RJ. Co-infection with Mycobacterium tuberculosis and human immunodeficiency virus: an overview and motivation for systems approaches. Pathog Dis. 2013;69(2):101-113.

13. Ndiaye BP, et al. Safety, immunogenicity, and efficacy of the candidate tuberculosis vaccine MVA85A in healthy adults infected with HIV-1: a randomised, placebo-controlled, phase 2 trial. Lancet Respir Med. 2015;3(3):190-200.

14. Tameris MD, et al. Safety and efficacy of MVA85A, a new tuberculosis vaccine, in infants previously vaccinated with BCG: a randomised, placebo-controlled phase $2 \mathrm{~b}$ trial. Lancet. 2013;381(9871):1021-1028.

15. Gillespie SH, et al. Four-month moxifloxacin-based regimens for drug-sensitive tuberculosis. N Engl JMed. 2014;371(17):1577-1587.

16. Majlessi L, Prados-Rosales R, Casadevall A, Brosch R. Release of mycobacterial antigens. Immunol Rev. 2015;264(1):25-45.

17. Comas I, et al. Human T cell epitopes of Mycobacterium tuberculosis are evolutionarily hyperconserved. Nat Genet. 2010;42(6):498-503.

18. Dustin ML, Depoil D. New insights into the T cell synapse from single molecule techniques. Nat Rev Immunol. 2011;11(10):672-684.

19. Sun J, Lanier L. NK cell development, homeostasis and function: parallels with $\mathrm{CD} 8^{+} \mathrm{T}$ cells. Nat Rev Immunol. 2011;11(10):645-657.

20. O'Donnell H, et al. Toll-like receptor and inflammasome signals converge to amplify the innate bactericidal capacity of T helper 1 cells. Immunity 2014;40(2):213-224.

21. Kupz A, et al. NLRC4 inflammasomes in dendritic cells regulate noncognate effector function by memory CD8(+) T cells. Nat Immunol. 2012;13(2):162-169.

22. Kastenmüller W, Torabi-Parizi P, Subramanian N, Lämmermann T, Germain Ronald N. A spatially-organized multicellular innate immune response in lymph nodes limits systemic pathogen spread. Cell. 2012;150(6):1235-1248.

23. Soudja SM, Ruiz A, Marie J, Lauvau G. Inflammatory monocytes activate memory $\mathrm{CD} 8(+) \mathrm{T}$ and innate NK lymphocytes independent of cognate antigen during microbial pathogen invasion. Immunity. 2012;37(3):549-562.

24. Berg RE, Crossley E, Murray S, Forman J. Memory $\mathrm{CD} 8^{+} \mathrm{T}$ cells provide innate immune protection against Listeria monocytogenes in the absence of cognate antigen. J Exp Med. 2003;198(10):1583-1593.

25. Kambayashi T, Assarsson E, Lukacher AE, Ljunggren HG, Jensen PE. Memory CD $8^{+} \mathrm{T}$ cells provide an early source of IFN- $\gamma$. JImmunol. 2003;170(5):2399-2408.

26. Schroder K, Tschopp J. The inflammasomes. Cell. 2010;140(6):821-832.

27. Mayer-Barber KD, et al. Caspase-1 independent $\mathrm{IL}-1 \beta$ production is critical for host resistance to mycobacterium tuberculosis and does not require TLR signaling in vivo. J Immunol. 2010;184(7):3326-3330.

28. Schneider B, et al. A role for IL-18 in protective immunity against Mycobacterium tuberculosis. Eur J Immunol. 2010;40(2):396-405.

29. Saiga H, et al. Critical role of AIM2 in Mycobacterium tuberculosis infection. Int Immunol. 2012;24(10):637-644.

30. Helbig ET, Opitz B, Sander LE. Adjuvant immunotherapies as a novel approach to bacterial infections. Immunotherapy. 2013;5(4):365-381.

31. Soudja SM, Chandrabos C, Yakob E, Veenstra M, Palliser D, Lauvau G. Memory-T-cellderived interferon- $\gamma$ instructs potent innate cell activation for protective immunity. Immunity. 2014;40(6):974-988.

32. Cooper AM, Dalton DK, Stewart TA, Griffin JP, Russell DG, Orme IM. Disseminated tuberculosis in interferon $\gamma$ gene-disrupted mice. J Exp Med. 1993;178(6):2243-2247.

33. Feng CG, et al. NK NK cell-derived IFN- $\gamma$ differentially regulates innate resistance and neutrophil response in $\mathrm{T}$ cell-deficient hosts infected with Mycobacterium tuberculosis. JImmunol. 2006;177(10):7086-7093.

34. Pircher H, Burki K, Lang R, Hengartner H, Zinkernagel RM. Tolerance induction in double specific T-cell receptor transgenic mice varies with antigen. Nature. 1989;342(6249):559-561.

35. Hogquist KA, Jameson SC, Heath WR, Howard JL, Bevan MJ, Carbone FR. T cell receptor antagonist peptides induce positive selection. Cell. 1994;76(1):17-27.

36. Waithman J, Gebhardt T, Davey GM, Heath WR, Carbone FR. Cutting edge: enhanced IL-2 signaling can convert self-specific $\mathrm{T}$ cell response from tolerance to autoimmunity. Jimmunol. 2008;180(9):5789-5793.

37. Kim M, Harty J. Splenectomy alters distribution and turnover but not numbers or protective capacity of de novo generated memory CD8 T cells. Front Immunol. 2014;5:568.

38. Sallusto F, Geginat J, Lanzavecchia A. Central memory and effector memory $\mathrm{T}$ cell subsets: function, generation, and maintenance. Annu Rev Immunol. 2004;22:745-763.

39. Kedzierska K, La Gruta NL, Stambas J, Turner SJ, Doherty PC. Tracking phenotypically and func- 
tionally distinct $\mathrm{T}$ cell subsets via $\mathrm{T}$ cell repertoire diversity. Mol Immunol. 2008;45(3):607-618.

40. Turner J, et al. A limited antigen-specific cellular response is sufficient for the early control of Mycobacterium tuberculosis in the lung but is insufficient for long-term survival. Infect Immun. 2004;72(7):3759-3768.

41. Hsu T, et al. The primary mechanism of attenuation of bacillus Calmette-Guerin is a loss of secreted lytic function required for invasion of lung interstitial tissue. Proc Natl Acad Sci U S A. 2003;100(21):12420-12425.

42. Behr MA, et al. Comparative genomics of BCG vaccines by whole-genome DNA microarray. Science. 1999;284(5419):1520-1523.

43. Pym AS, et al. Recombinant BCG exporting ESAT- 6 confers enhanced protection against tuberculosis. Nat Med. 2003;9(5):533-539.

44. Brodin $\mathrm{P}$, et al. Functional analysis of early secreted antigenic target- 6 , the dominant T-cell antigen of Mycobacterium tuberculosis, reveals key residues involved in secretion, complex formation, virulence, and immunogenicity. J Biol Chem. 2005;280(40):33953-33959.

45. Majlessi L, et al. Influence of ESAT-6 secretion system 1 (RD1) of Mycobacterium tuberculosis on the interaction between mycobacteria and the host immune system. JImmunol. 2005;174(6):3570-3579.

46. Lewis KN, et al. Deletion of RD1 from Mycobacterium tuberculosis mimics bacille Calmette-Guerin attenuation. J Infect Dis. 2003;187(1):117-123.

47. Simeone R, et al. Phagosomal rupture by Mycobacterium tuberculosis results in toxicity and host cell death. PLoS Pathog. 2012;8(2):e1002507.

48. Rathinam VA, et al. TRIF licenses caspase-11dependent NLRP3 inflammasome activation by gram-negative bacteria. Cell. 2012;150(3):606-619.

49. Collins AC, et al. Cyclic GMP-AMP synthase is an innate immune DNA sensor for Mycobacterium tuberculosis. Cell Host Microbe. 2015;17(6):820-828.

50. Wassermann R, et al. Mycobacterium tuberculosis differentially activates cGAS- and inflammasome-dependent intracellular immune responses through ESX-1. Cell Host Microbe. 2015;17(6):799-810.

51. Watson RO, et al. The cytosolic sensor cGAS detects Mycobacterium tuberculosis DNA to induce type I interferons and activate autophagy. Cell Host Microbe. 2015;17(6):811-819.

52. Mishra BB, et al. Nitric oxide controls the immunopathology of tuberculosis by inhibiting NLRP3 inflammasome-dependent processing of IL- $1 \beta$. Nat Immunol. 2013;14(1):52-60.

53. Watt SV, Andrews DM, Takeda K, Smyth MJ, Hayakawa Y. IFN- $\gamma$-dependent recruitment of mature CD27(high) NK cells to lymph nodes primed by dendritic cells. JImmunol. 2008;181(8):5323-5330.

54. Li ZY, et al. IFN- $\gamma$ induces aberrant CD49b(+) NK cell recruitment through regulating CX3CL1: a novel mechanism by which IFN- $\gamma$ provokes pregnancy failure. Cell Death Dis. 2014;5:e1512.

55. Mishra BB, et al. Mycobacterium tuberculosis protein ESAT- 6 is a potent activator of the
NLRP3/ASC inflammasome. Cell Microbiol. 2010;12(8):1046-1063.

56. Houben D, et al. ESX-1-mediated translocation to the cytosol controls virulence of mycobacteria. Cell Microbiol. 2012;14(8):1287-1298.

57. Brandt L, Oettinger T, Holm A, Andersen AB, Andersen P. Key epitopes on the ESAT- 6 antigen recognized in mice during the recall of protective immunity to Mycobacterium tuberculosis. J Immunol. 1996;157(8):3527-3533.

58. Rao M, Vogelzang A, Kaiser P, Schuerer S, Kaufmann SH, Gengenbacher M. The tuberculosis vaccine candidate Bacillus Calmette-Guerin DeltaureC::hly coexpressing human interleukin-7 or -18 enhances antigen-specific $\mathrm{T}$ cell responses in mice. PLoS One. 2013;8(11):e78966.

59. Kaufmann SH. Tuberculosis vaccines: time to think about the next generation. Semin Immunol. 2013;25(2):172-181.

60. De Gregorio E, D'Oro U, Wack A. Immunology of TLR-independent vaccine adjuvants. Curr Opin Immunol. 2009;21(3):339-345.

61. Li H, Willingham S, Ting JPY, Re F. Cutting edge: inflammasome activation by alum and alum's adjuvant effect are mediated by NLRP3. JImmunol. 2008;181(1):17-21.

62. Petrovsky N, Aguilar JC. Vaccine adjuvants: Current state and future trends. Immunol Cell Biol. 2004;82(5):488-496.

63. Saiga $\mathrm{H}$, et al. The recombinant BCG $\triangle$ ureC::hly vaccine targets the AIM2 inflammasome to induce autophagy and inflammation. J Infect Dis. 2015;211(11):1831-1841.

64. Pym AS, Brodin P, Brosch R, Huerre M, Cole ST. Loss of RD1 contributed to the attenuation of the live tuberculosis vaccines Mycobacterium bovis BCG and Mycobacterium microti. Mol Microbiol. 2002;46(3):709-717.

65. Bottai D, et al. Increased protective efficacy of recombinant BCG strains expressing virulenceneutral proteins of the ESX-1 secretion system. Vaccine. 2015;33(23):2710-2718.

66. Brodin P, et al. Enhanced protection against tuberculosis by vaccination with recombinant Mycobacterium microti vaccine that induces $\mathrm{T}$ cell immunity against region of difference 1 antigens. J Infect Dis. 2004;190(1):115-122.

67. Helft J, et al. GM-CSF mouse bone marrow cultures comprise a heterogeneous population of $\mathrm{CD} 11 \mathrm{c}(+) \mathrm{MHCII}(+)$ macrophages and dendritic cells. Immunity. 2015;42(6):1197-1211.

68. Bachem A, et al. Superior antigen crosspresentation and XCR1 expression define human $\mathrm{CD} 11 \mathrm{c}^{+} \mathrm{CD} 141^{+}$cells as homologues of mouse CD8 $8^{+}$dendritic cells. JExp Med. 2010;207(6):1273-1281.

69. Haniffa M, et al. Human tissues contain CD141 ${ }^{\text {hi }}$ cross-presenting dendritic cells with functional homology to mouse $\mathrm{CD}_{103}{ }^{+}$nonlymphoid dendritic cells. Immunity. 2012;37(1):60-73.

70. van der Wel N, et al. M. tuberculosis and M. leprae translocate from the phagolysosome to the cytosol in myeloid cells. Cell. 2007;129(7):1287-1298.

71. Simeone R, et al. Cytosolic access of Mycobacterium tuberculosis: critical impact of phagosomal acidification control and demonstration of occurrence in vivo. PLoS Pathog. 2015;11(2):e1004650.

72. Bijker EM, et al. Protection against malaria after immunization by chloroquine prophylaxis and sporozoites is mediated by preerythrocytic immunity. Proc Natl Acad Sci U S A. 2013;110(19):7862-7867.

73. Cheong C, et al. Improved cellular and humoral immune responses in vivo following targeting of HIV Gag to dendritic cells within human antihuman DEC205 monoclonal antibody. Blood. 2010;116(19):3828-3838.

74. Silva-Sanchez A, et al. ESAT-6 targeting to $\mathrm{DEC} 25^{+}$antigen presenting cells induces specific-T cell responses against ESAT- 6 and reduces pulmonary infection with virulent Mycobacterium tuberculosis. PLoS One. 2015;10(4):e0124828.

75. Tschopp J, Schroder K. NLRP3 inflammasome activation: the convergence of multiple signalling pathways on ROS production? Nat Rev Immunol. 2010;10(3):210-215.

76. Flach T, et al. Alum interaction with dendritic cell membrane lipids is essential for its adjuvanticity. Nat Med. 2011;17(4):479-487.

77. Cebrian I, et al. Sec22b regulates phagosomal maturation and antigen crosspresentation by dendritic cells. Cell. 2011;147(6):1355-1368.

78. Zehner M, et al. The translocon protein Sec61 mediates antigen transport from endosomes in the cytosol for cross-presentation to $\mathrm{CD} 8^{+} \mathrm{T}$ cells. Immunity. 2015;42(5):850-863.

79. Coll RC, et al. A small-molecule inhibitor of the NLRP3 inflammasome for the treatment of inflammatory diseases. Nat Med. 2015;21(3):248-255.

80. Conforti-Andreoni C, Ricciardi-Castagnoli P, Mortellaro A. The inflammasomes in health and disease: from genetics to molecular mechanisms of autoinflammation and beyond. Cell Mol Immunol. 2011;8(2):135-145.

81. Hoffman H, Brydges S. The genetic and molecular basis of inflammasome-mediated disease. J Biol Chem. 2011;286(13):10889-10896.

82. Huntington ND, et al. IL-15 trans-presentation promotes human NK cell development and differentiation in vivo. JExp Med. 2009;206(1):25-34.

83. Jakobs C, Perner S, Hornung V. AIM2 drives joint inflammation in a self-DNA triggered model of chronic polyarthritis. PLoS One. 2015;10(6):e0131702.

84. Parra M, et al. Development of a murine mycobacterial growth inhibition assay for evaluating vaccines against Mycobacterium tuberculosis. Clin Vaccine Immunol. 2009;16(7):1025-1032.

85. Pegram HJ, Jackson JT, Smyth MJ, Kershaw MH, Darcy PK. Adoptive transfer of genemodified primary NK cells can specifically inhibit tumor progression in vivo. JImmunol. 2008;181(5):3449-3455.

86. Lochner M, Wagner H, Classen M, Forster I. Generation of neutralizing mouse anti-mouse IL-18 antibodies for inhibition of inflammatory responses in vivo. J Immunol Methods. 2002;259(1-2):149-157. 